\title{
AN IN VITRO STUDY OF RADIATION DOSE ENHANCEMENT USING GOLD NANORODS AND PLASMONIC PHOTOTHERMAL THERAPY
}

\author{
by \\ Daniel DiCenzo \\ B.Sc. University of Toronto 2014 \\ Toronto, Canada
}

\begin{abstract}
A thesis
presented to Ryerson University

in partial fulfillments of the

requirements for the degree of

Master of Science

in the program of

Biomedical Physics
\end{abstract}

Toronto, Ontario, Canada, 2016

(C) Daniel DiCenzo, 2016 


\section{Author's Declaration}

I hereby declare that I am the sole author of this thesis. This is a true copy of the thesis, including any required final revisions, as accepted by my examiners.

I authorize Ryerson University to lend this thesis to other institutions or individuals for the purpose of scholarly research.

I further authorize Ryerson University to reproduce this thesis by photocopying or by other means, in total or in part, at the request of other institutions or individuals for the purpose of scholarly research.

I understand that my thesis may be made electronically available to the public.

\section{Daniel DiCenzo}




\author{
Abstract \\ An in vitro study of radiation dose enhancement using gold nanorods and \\ plasmonic photothermal therapy \\ Daniel DiCenzo \\ Master of Science, Biomedical Physics \\ Ryerson University, 2016
}

Gold nanoparticles (GNP) have been shown to highly absorb ionizing radiation compared to tissue. GNPs have also been shown to be high absorbers of non-ionizing radiation with a peak absorbance at a wavelength dependent on their shape and size. This study investigated radiation dose enhancement in PC3 cells when in the presence of gold nanorods (NR) and near infrared light (IR). The PC3 cells were incubated with either PEGylated NRs (PNR) or anti prostate stem cell antigen antibody with nuclear localization sequence peptide conjugated NRs (AbNR). They were exposed to near infrared light at a wavelength of $810 \mathrm{~nm}$ to achieve a temperature of $42{ }^{\circ} \mathrm{C}$ to $43{ }^{\circ} \mathrm{C}$ for 60 minutes. They were also exposed to $160 \mathrm{kVp}$ x-rays. It was found that both targeted and non-targeted GNPs when exposed to radiation and near infrared light synergistically enhanced radiation dose. It was also found that AbNRs provide greater dose enhancement than PNRs. 


\section{Acknowledgements}

This thesis would not be possible without the help of my supervisors Dr. Claire McCann and Dr. Carl Kumaradas as well as my other supervisory committee members,

Dr. Michael Kolios and Dr. Raffi Karshafian. Their guidance and expert knowledge kept me in the right direction these past two years.

I would like to thank Dr. Gregory Czarnota for allowing me to use his cell lab and supplies in order for me to complete my experiments. Dr. Czarnota's staff have been incredibly helpful, most notably Azza Al-Mahrouki and Anoja Giles. Thank you Azza for showing me everything I needed to know about cell culturing and optimizing the setup of my experiments. Azza and Anoja were always there to offer help when I needed it.

Finally, I'd like to thank my friends and family for understanding my busy schedule and being there for I needed a break from research. 


\section{Table of Contents}

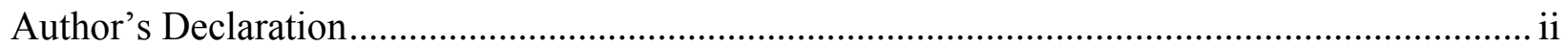

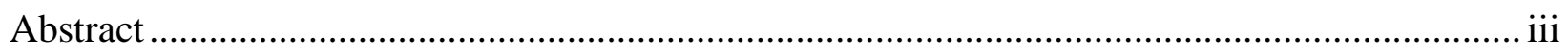

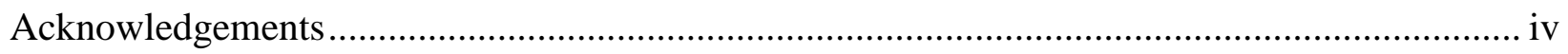

Table of Contents ............................................................................................................

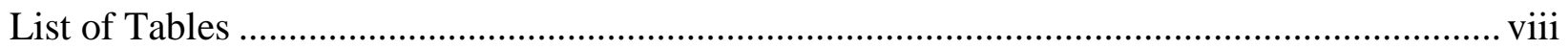

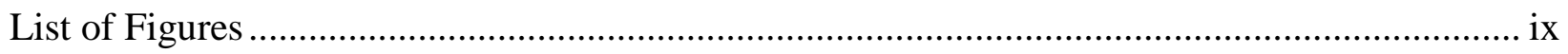

Symbols and Abbreviations ........................................................................................

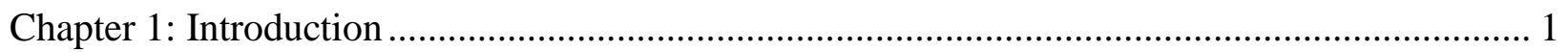

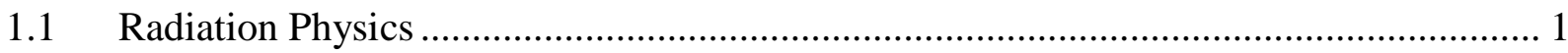

1.1.1 Biological effects of radiation (Radiobiology) ............................................. 2

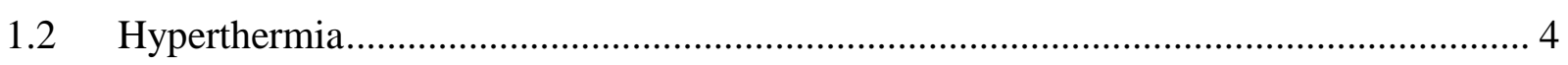

1.2.1 Hyperthermia as a radiosensitizer ............................................................... 6

1.2.2 Oxygen as a radiation enhancer ............................................................... 8

1.2.3 Hyperthermia and Radiation treatment schedule .......................................... 8

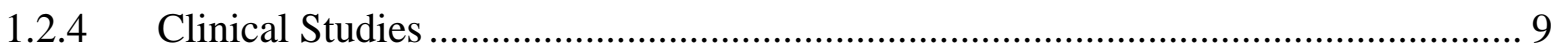

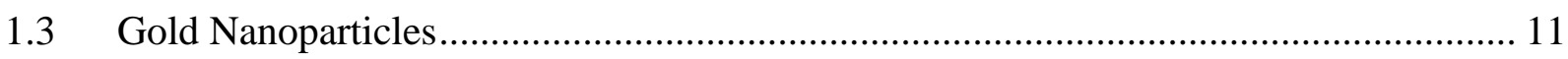

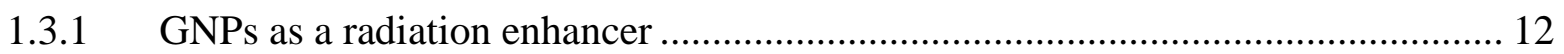

1.3.2 Use of Gold Nanoparticles in Photothermal Therapy ........................................ 14

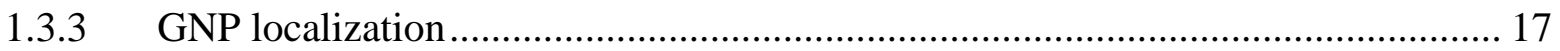


1.4 Studies using hyperthermia, GNPs and radiation together.

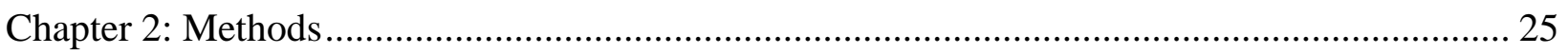

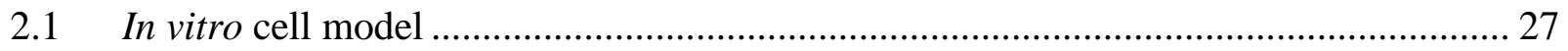

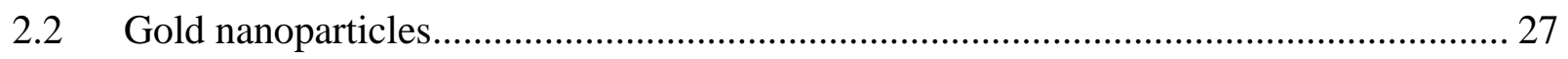

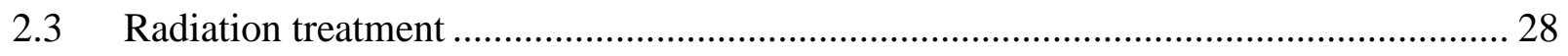

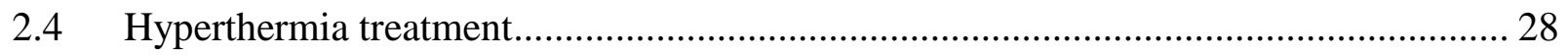

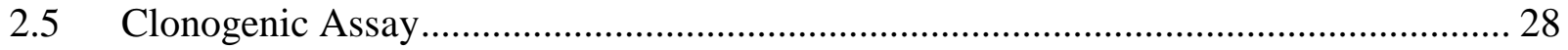

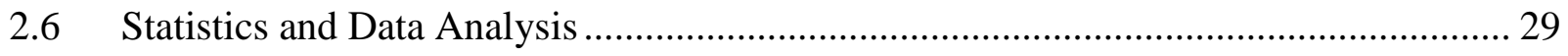

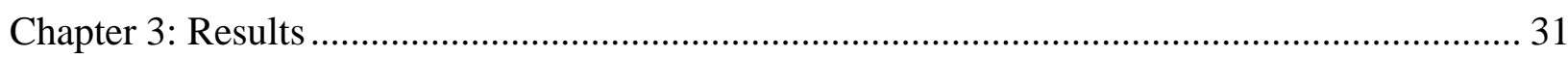

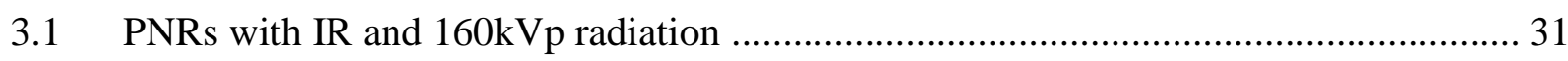

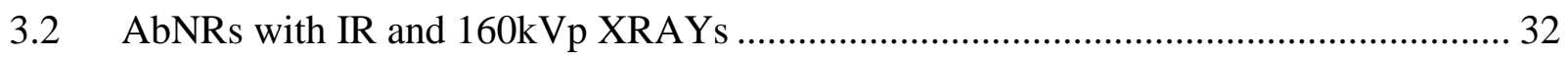

3.3 Scheduling of GNPs, radiation and IR light................................................... 34

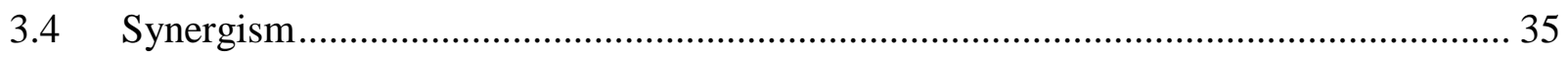

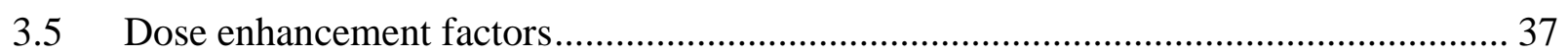

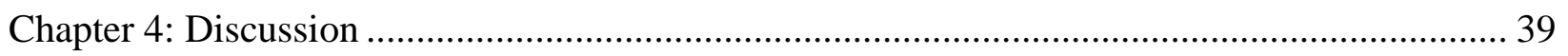

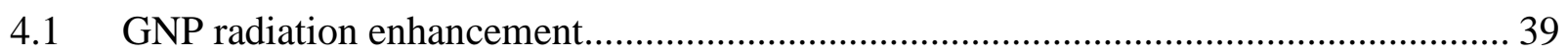

4.1.1 Comparison of DEF using GNPs and Radiation............................................... 39

4.1.2 Dependence of DEF and GNP Localization in the Cell ................................... 40

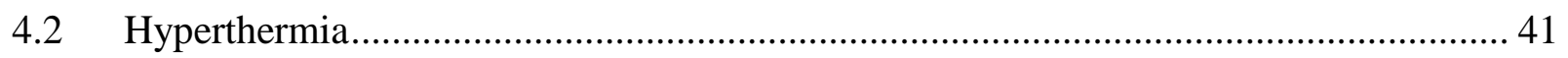

4.3 Production of Heat using GNPs and IR light .................................................. 41 
4.4 Hyperthermia and radiation scheduling vs dose enhancement ................................ 42

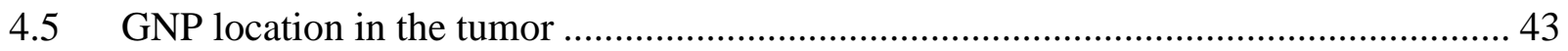

Chapter 5: Conclusions and Future Work........................................................................... 44

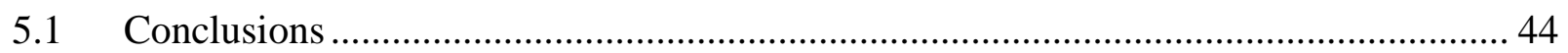

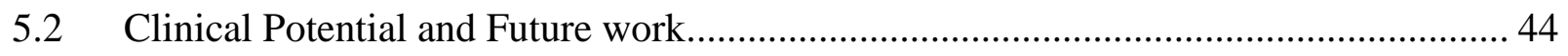

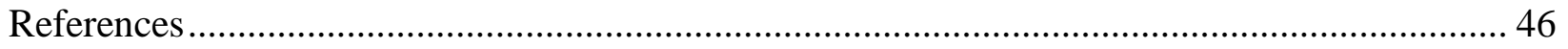




\section{List of Tables}

Table 1: List of experiments completed. 


\section{List of Figures}

Figure 1: Interaction of ionizing radiation with DNA.

Figure 2: Cell survival at various heating temperatures and times in vitro (C3H mammalian cells).

Figure 3: The effectiveness of treatment at different intervals between heat and radiation.

Figure 4: Mass attenuation coefficient indicating photon interactions in gold at photon energies from $10^{-8} \mathrm{MeV}$ to $10^{4} \mathrm{MeV}$.

Figure 5: Oscillation of the conduction band electrons against an oscillating electric field.

Figure 6: Distribution of GNPs in mice using targeted (T) or non-targeted (NT) GNPs through intravenous or intratumoral injection.

Figure 7: Experimental set up to deliver simultaneous radiation and IR light to the PC3 cells.

Figure 8: Timeline showing the delivery of XRAYs with respect to IR.

Figure 9: Cell survival fraction compared using XRAY (*), PNR/XRAY ( $\mathbf{A})$, $\mathrm{PNR} / \mathrm{XRAY}_{+4} / \mathrm{IR}(\nabla)$ and $\mathrm{PNR} / \mathrm{XRAY}_{0} / \mathrm{IR}(\odot)$.

Figure 10: Cell survival curves displaying XRAY alone (*), $\operatorname{AbNR} / \operatorname{XRAY}(\mathbf{\Delta})$, $\mathrm{AbNR} \mathrm{XRAY}_{+4} / \mathrm{IR}(\boldsymbol{\nabla})$ and $\mathrm{AbNR} / \mathrm{XRAY}_{0} / \mathrm{IR}(\odot)$.

Figure 11: Cell survival for treatments which did not involve radiation. 
Figure 12: Cell survival curves displaying AbNR/XRAY ( $\mathbf{\Delta}), \operatorname{AbNR} / X R A Y$.

${ }_{120} / \mathrm{IR}(*), \mathrm{AbNR}_{\mathrm{XRAY}}{ }_{+120} / \mathrm{IR}(*), \mathrm{AbNR} \mathrm{XRAY}_{-60} / \mathrm{IR}(\boldsymbol{\Delta})$,

$\mathrm{AbNR}_{\mathrm{XRAY}}+60 / \mathrm{IR}(\mathbf{\Delta}), \mathrm{AbNR}_{\mathrm{XRAY}}{ }_{+4} / \mathrm{IR}(\boldsymbol{\nabla})$ and $\mathrm{AbNR}_{\mathrm{XRRAY}} / \mathrm{IR}(\mathbf{O})$.

Figure 13: Survival curves comparing experimental results and projected additive cell survival using PNRs.

Figure 14: Survival curves comparing experimental results and projected additive cell survival using AbNRs.

Figure 15: DEFs for various treatments. 


\section{Symbols and Abbreviations}

DNA - deoxyribonucleic acid

CEM - cumulative equivalent minutes

TRUS - transrectal ultrasound

TER - thermal enhancement ratio

TGF - therapeutic gain factor

$\mathrm{CR}$ - complete response

OS - overall survival

DFS - disease free survival

HDR - high dose rate

$\mathrm{RF}$ - radiofrequency

Ir-192 - Iridium 192

GNP - gold nanoparticle

NR - nanorod

PPTT - photothermal therapy

RME - receptor mediated endocytosis

PSCA - prostate stem cell antigen

PEG - polyethylene glycol 
AbNR - gold nanorod conjugated with anti-PSCA antibody and NLS peptide for targeted NR delivery

PNR - gold nanorod conjugated with PEG, non-targeted

NLS - nuclear localization sequence

XRAY - ionizing radiation

IR - near infrared light

AbNR/XRAY $0 / I R$ - Antibody and NLS peptide conjugated NRs plus radiation applied in the middle of IR treatment

AbNR/XRAY ${ }_{+} / \mathrm{IR}$ - Antibody and NLS peptide conjugated NRs plus radiation applied 4 minutes after IR treatment

AbNR/XRAY+60/IR - Antibody and NLS peptide conjugated NRs plus radiation applied 60 minutes after IR treatment

AbNR/XRAY ${ }_{+120} / \mathrm{IR}$ - Antibody and NLS peptide conjugated NRs plus radiation applied 120 minutes after IR treatment

AbNR/XRAY-60/IR - Antibody and NLS peptide conjugated NRs plus radiation applied 60 minutes before IR treatment

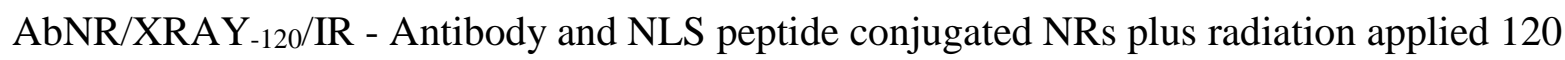
minutes before IR treatment

DEF - dose enhancement factor 
$\mathrm{DEF}_{10 \%}$ - dose enhancement factor at $10 \%$ cell survival

PBS - Phosphate Buffered Saline

PPTT - plasmonic photothermal therapy 


\section{Chapter 1: Introduction}

\subsection{Radiation Physics}

Ionizing radiation is one of the primary treatment options for patients with various types of cancer. Radiation therapy can be applied using a variety of different sources which emit ionizing radiation. These include external x-rays, charged particle radiation (electrons and protons) and gamma rays from radioactive sources.

The interaction of ionizing radiation within an absorbing medium can result in an exchange of energy from the radiation to the medium. The energy exchange can result in ionization of the molecules in the medium. This radiation can be split into two categories, directly ionizing and indirectly ionizing. Directly ionizing radiation is in the form of charged particles such as electrons, protons or alpha particles. ${ }^{1}$ These particles can directly transfer their energy to the medium through ionization or excitation. Indirectly ionizing radiation is in the form of uncharged particles and must first interact with the absorbing material to allow for the creation of charged particles. These charged particles can then induce ionization events in the absorbing material. An example of indirectly ionizing radiation are high energy photons which are massless packets of energy and can undergo many types of interactions with an absorbing medium. The three main interactions include the photoelectric effect, Compton effect and pair production. ${ }^{2}$

The photoelectric effect involves the complete absorption of a photon in an atom. This results in the emission of a bound electron, known as a photoelectron, with a kinetic energy $\left(T_{P E}\right) . T_{P E}$ is related to the energy of the incident photon $h v$ and the binding energy $E_{n}$ of an electron in the 
$n^{\text {th }}$ atomic orbital. It is given by $T_{\mathrm{PE}}=h v+E_{n}$. With the removal of a bound electron, an electron from the next higher orbital $(n+1)$ will de-excite to the lower orbital and in this process, emit a photon known as a characteristic $\mathrm{x}$-ray. The energy of this $\mathrm{x}$-ray $h v_{\text {char }}$ will have an energy given by $h v_{\text {char }}=E_{n+1}-E_{n}$.

It is also possible that the emitted characteristic x-ray collides with an electron in a higher orbital $m$, resulting in the absorption of the characteristic x-ray and the emission of an Auger electron with energy $T_{\text {Auger }}=h v_{\text {char }}+E_{m} \cdot^{3}$

The Compton effect occurs when the incident photon interacts with a loosely bound electron in the absorbing atom. The result is a scattered photon and scattered electron, also known as a Compton electron. If the photon has sufficient energy $\left(>2 m_{e} c^{2}\right)$ and interacts with the nucleus of the absorbing atom, pair production can occur. In this case, the photon is completely absorbed in the atom and an electron-positron pair is produced. The positron $\left(\mathrm{e}^{+}\right)$will travel until it is annihilated, where two gamma rays will be emitted. In order for pair production to occur, the incident photon must have a minimum energy of $2 m_{e} c^{2}$, where $m_{e}$ is the resting mass of an electron and $c$ is the speed of light in a vacuum. ${ }^{3}$

\subsubsection{Biological effects of radiation (Radiobiology)}

When radiation interacts with living tissue it can result in direct cell death or the loss of cell proliferation. While all components of the cell are vulnerable to the effects of radiation, it is the damage to the DNA which is most critical. This is due to the fact that damage to the DNA can result in the inhibition of cell replication. The most effective ways radiation can damage DNA is by the production of single strand or double strand breaks in the DNA structure. Figure 1 shows the interaction of x-rays with a nanoparticle or tissue to produce charged particles or free 
radicals which can go on to induce DNA strand breaks. These strand breaks can occur by direct or indirect action. ${ }^{1}$ If direct action occurs, the energy from the secondary ion produced may be deposited directly to the DNA. This can result in excitation or ionization of the DNA molecule which can lead to a strand break. Indirect action relies on the production of a free radical to induce damage to the DNA. The production of free radicals by radiation in biological tissue is mainly due to the radiolysis of water. ${ }^{4}$

Since tissue is comprised mostly of water $\left(\mathrm{H}_{2} \mathrm{O}\right)$, the secondary ions produced from the photon can ionize or excite the water molecules resulting in the production of free radicals. The most common free radical is the hydroxyl radical $(\mathrm{OH} \cdot)$. The free radicals can diffuse and reach the DNA to induce a chemical reaction. ${ }^{4}$ The radical which is responsible for the most damage to the DNA is the hydroxyl radical. Chatterjee and Holley performed Monte Carlo simulations to determine how the hydroxyl radical and other free radicals can induce DNA damage. ${ }^{5}$ One of the main reactions is a hydrolysis reaction where the free radical combines with a hydrogen atom on the phosphate backbone of the DNA, damaging the structure of the backbone and creating water. This damage to the backbone can result in a single strand break (SSB) and if two SSBs occur within 10 base pairs of one another, a double strand break may occur. ${ }^{4}$ 


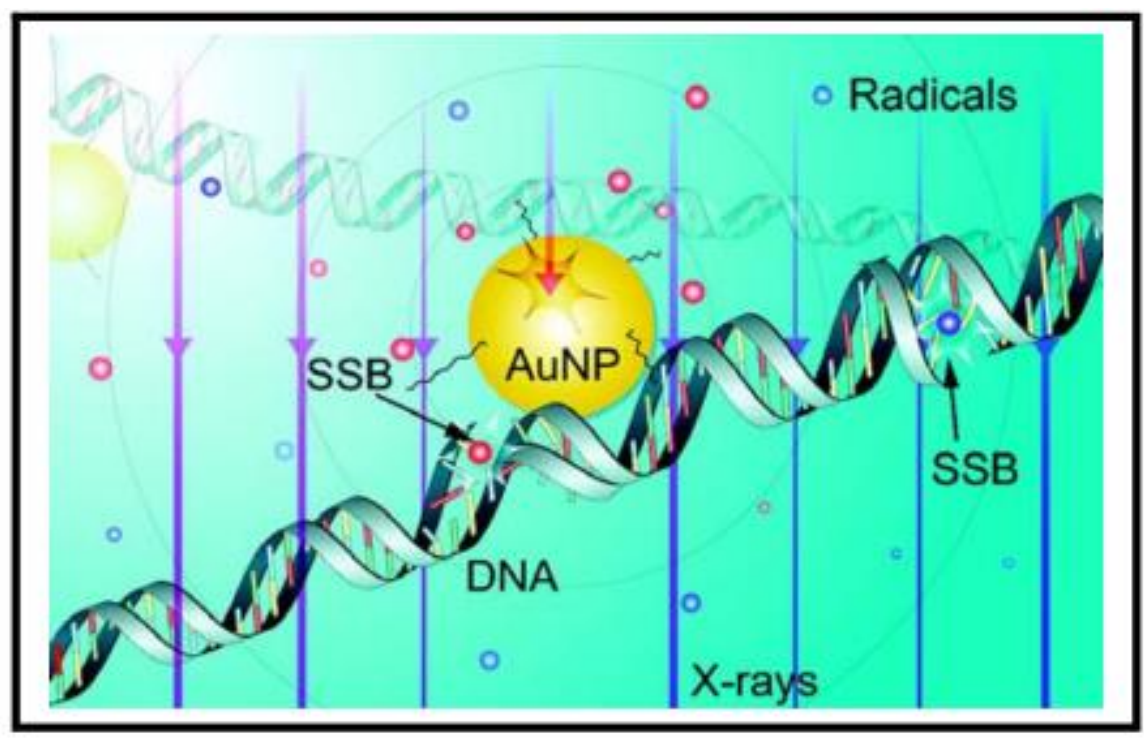

Figure 1: GNP interaction with photon to produce photoelectrons and auger electrons. Along with the free radicals produced with the photon interaction with water, these particles can result in single strand breaks (SSB) or double strand breaks (DSB). The figure is replicated from Carter et. al. ${ }^{6}$

\subsection{Hyperthermia}

It is well known that the tumor environment can be acidic, hypoxic and nutritionally deprived. ${ }^{7-9}$ The nature of these environments cause tumors to be resistant to the effects of radiation. However, it is this same environment which makes tumors more sensitive to heating compared to normal tissue. ${ }^{10,11}$ In the past few decades, heat as treatment for tumors has been investigated. One such method is using hyperthermia treatment to heat the tumor region to between $41^{\circ} \mathrm{C}$ to $45^{\circ} \mathrm{C}$ for $30 \mathrm{~min}$ to $60 \mathrm{~min}$.

The biological effects of hyperthermia have been investigated since the 1970s. Initially, studies had investigated the cytotoxic effects of hyperthermia on mammalian cell lines. These studies showed a relation between cell survival, heating time and temperature. ${ }^{12-14}$ Figure 2 shows that cell survival decreases with increasing heating temperature and duration. ${ }^{1}$ 


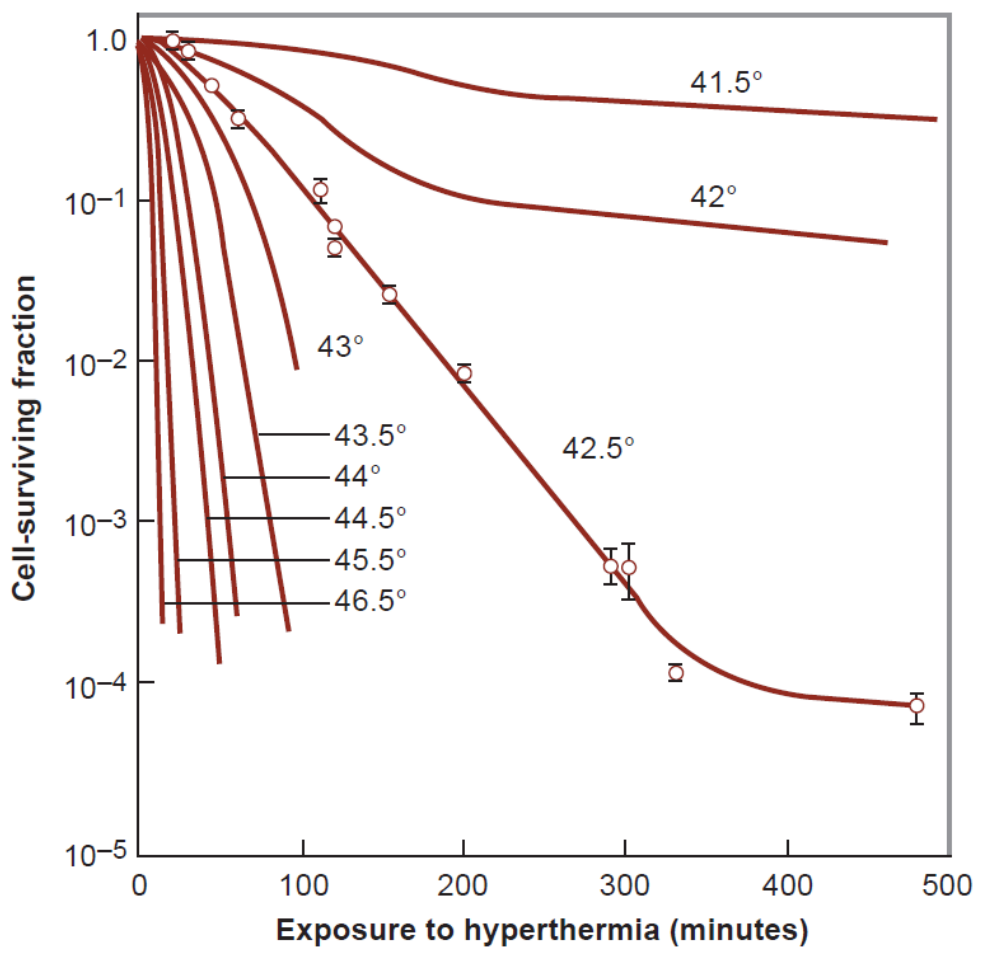

Figure 2: Cell survival at various temperature exposures and durations in vitro $(\mathrm{C} 3 \mathrm{H}$ mammalian cells). The figure is replicated from Hall et.al. ${ }^{1}$

While temperatures above $41^{\circ} \mathrm{C}$ showed exponential cell death increasing with heating time, the rate of cell death was dependent on the heating temperature. Sapareto and Dewey introduced the concept of thermal dose and the relation between the effectiveness of heating with temperature and time. In this case, thermal dose is expressed as the time taken to achieve the same thermal effect at $43^{\circ} \mathrm{C} .{ }^{15}$ This is known as cumulative equivalent minutes $\left(\mathrm{CEM}_{43}\right)$ and the relationship is given by

$$
C E M_{43}=\int_{0}^{t} R^{T(t)-43^{\circ} \mathrm{C}} d t
$$

where $t$ is the duration of heating (in min) and $R=\left\{\begin{array}{c}0.5 \text { for } T \geq 43^{\circ} \mathrm{C} \\ 0.25 \text { for } T<43^{\circ} \mathrm{C}\end{array}\right.$. 
From this relationship, one can deduce that with each $1^{\circ} \mathrm{C}$ increase in temperature $\geq 43^{\circ} \mathrm{C}$ the time required to achieve the same thermal effect is halved. With each $1^{\circ} \mathrm{C}$ increase in heating temperature below $43^{\circ} \mathrm{C}$, the time required to achieve the same thermal effect is reduced to one quarter. $C E M_{43}$ is used clinically to determine the accumulated thermal dose to the patient. ${ }^{16}$ While it has been shown that hyperthermia has the ability to induce direct cell death, it has not been shown to be effective as a monotherapy. ${ }^{17}$ Instead, hyperthermia is used as an adjuvant therapy in conjunction with radiation and/or chemotherapy.

\subsubsection{Hyperthermia as a radiosensitizer}

A number of in vitro, in vivo and clinical studies have investigated the dose enhancing abilities of applying hyperthermia in conjunction with radiation. These were completed using a range of thermal and radiation doses. ${ }^{18-21}$ Ryu et. al. performed an in-vitro study on the cell survival of different cancer cell lines after receiving hyperthermia. It was found that the enhancement of radiation by thermal therapy is largely dependent on the type of cell. ${ }^{20} \mathrm{~A}$ clinical trial by Algan et. al. showed that hyperthermia treatment with radiation therapy is a viable treatment in prostate cancer, however, it did not show significant improvement in patient survival when compared to radiation therapy alone or radiation therapy with hormone therapy. ${ }^{22}$

Heating can be delivered externally from the body with a radiofrequency phased arrays or using high intensity focused ultrasound. ${ }^{23}$ Internalized heating methods have also been used, such as transrectal ultrasound (TRUS) and interstitial heating by microwave or radiofrequency emitting

catheters. $^{21,22,24}$ Radiation enhancement with hyperthermia may be limited in part to the limitations of the technologies used for heating. Maintenance of homogeneous and therapeutic temperatures are critical to the success of hyperthermia as a radiosensitizer. The inability to 
achieve therapeutic temperatures in the tumor may be a result of blood flow carrying heat away and the heterogeneous temperatures distribution may be due to non-uniform blood flow. The inhomogeneous temperature distribution during interstitial hyperthermia can result in hot or cold spots in the tissue with temperatures that can cause pain or pressure in the patient. ${ }^{10}$ As such, many clinical studies using interstitial hyperthermia have been limited in achieving their prescribed thermal dose..$^{25,26}$

Thermoradiosensitization is caused by direct and indirect effects. Direct sensitization occurs by hyperthermia's ability to inhibit a cell's recovery from sublethal damage caused by radiation induced DNA strand breaks. ${ }^{27,28}$ Hyperthermia can also increase blood flow and as a result, increases oxygen to the hypoxic tumor. ${ }^{29-31}$ The increase in oxygenation of the tumor enhances the effects of the radiation via the oxygen fixation hypothesis. ${ }^{19}$ The dependence of oxygen in radiation treatment is due to the fixation of DNA damage which results in a greater number of unrepaired DNA strand breaks in the cancer cells. The effectiveness of hyperthermia as a radiosensitizer is denoted as a thermal enhancement ratio (TER), which is defined as, $T E R=\frac{D_{\text {rad }}}{D_{\text {rad }+ \text { ht }}}$. Where $D_{\text {rad }}$ is the radiation dose to achieve a certain cell survival using only radiation and $D_{\text {rad+ht }}$ is the dose to achieve the same cell survival using radiation and hyperthermia. The TER is dependent on the temperature reached, the duration of heating and the interval between heat and radiation. ${ }^{23}$ It has been shown in various cell lines that the greatest thermal enhancement occurs when radiation is applied simultaneously with hyperthermia..$^{27,32-36}$ This effect can be seen in Figure 3. 


\subsubsection{Oxygen as a radiation enhancer}

Many studies have shown that the effectiveness of radiation is greater in conditions with high oxygen concentration compared to limited or no oxygen (hypoxic). In the case of cancerous tumors, many large tumors have hypoxic conditions due to the lack of blood flow which is a result of the tumor's poor vascular structure. These hypoxic conditions cause the tumors to be more resistant to the radiation exposure.

The ability for oxygen to enhance the effects of radiation is due to the "oxygen fixation hypothesis". This hypothesis states that when a free radical is produced, they may be stabilized by interacting with sulfhydryl compounds in the cell. This prevents the radicals from being effective and inducing DNA strand breaks. When oxygen is present, the $\mathrm{O}_{2}$ molecule can interact with the free radical and "fix it" to ensure that it can remain reactive. ${ }^{4}$

This can also be applied to DNA which has lost a hydrogen atom in the deoxyribose molecule and can undergo a single strand break. The DNA can be repaired chemically, by the interaction of the damaged DNA with a sulfhydryl molecule. If there is oxygen present, the oxygen has the ability to fix the DNA damage and not allow for chemical repair by the sulfhydryl molecule.

\subsubsection{Hyperthermia and Radiation treatment schedule}

As explained above, hyperthermia can enhance the effects of radiation when the two are applied together. However, it should be noted that the scheduling of the hyperthermia and radiation has a large impact on the thermal enhancement. ${ }^{33,34}$ An in vivo study by Overgaard, et. al., investigated the TER of both cancerous and healthy tissue in mice when hyperthermia and radiation were applied either simultaneously or sequentially. The sequential treatment involved the application of radiation either before or after hyperthermia. In this study, the time between 
radiation and hyperthermia was varied. As shown in Figure 3, when hyperthermia and radiation were applied, the TER for both healthy skin and the tumor were the highest compared to sequential treatment. It also showed that TER dropped off as the time between treatments increased.

This is due to both direct thermoradiosensitization and indirect sensitization. Direct sensitization occurs due to hyperthermia's ability to effect a cell's recovery from radiation induced DNA strand breaks. ${ }^{28}$ Indirect sensitization can occur due to increased blood flow resulting in increased oxygenation to the tumor.

Figure 3 also shows that when simultaneous treatment was applied, the TER for both were the same $($ TER $=2.45)$. When the treatment was sequential the skin resulted in less TER than the tumor tissue. The difference is noted as the therapeutic gain factor (TGF) and is important in ensuring that normal tissue remains as least affected as possible when the treatment is occurring. This TGF may be due to better and quicker repair of the healthy tissue versus the cancerous tissue after radiation or heat is applied. The poor repair of the tumor tissue may then make it more vulnerable to the effects of the next therapy modality. ${ }^{24}$

If one can achieve a very local dose of heat and radiation to the tumor tissue, simultaneous treatment is recommended as it can provide the greatest TER. However, if there is a risk of affecting the surrounding healthy tissue and providing it with too large of a dose, then sequential treatment is recommended as the TER for healthy tissue would be less than for the tumor.

\subsubsection{Clinical Studies}

A variety of clinical studies have been conducted using hyperthermia with radiation to treat various types of cancer in different organs of the body. While these studies apply both 
radiation and hyperthermia, the heating schedules and radiation treatment can vary. Overall, a majority of these clinical studies have shown that the use of hyperthermia and radiation offers greater complete response (CR), overall survival (OS) and disease free survival (DFS) compared to using hyperthermia or radiation alone..$^{18,22,25,26,37-41}$

While the results of these studies show very clearly that hyperthermia can offer radiation enhancement, they also show that the standard methods of delivering the hyperthermia result in heterogeneous temperature distribution and it is difficult to achieve high temperatures $\left(>43^{\circ} \mathrm{C}\right)$ for long periods of time (> $60 \mathrm{~min}){ }^{25}$ 


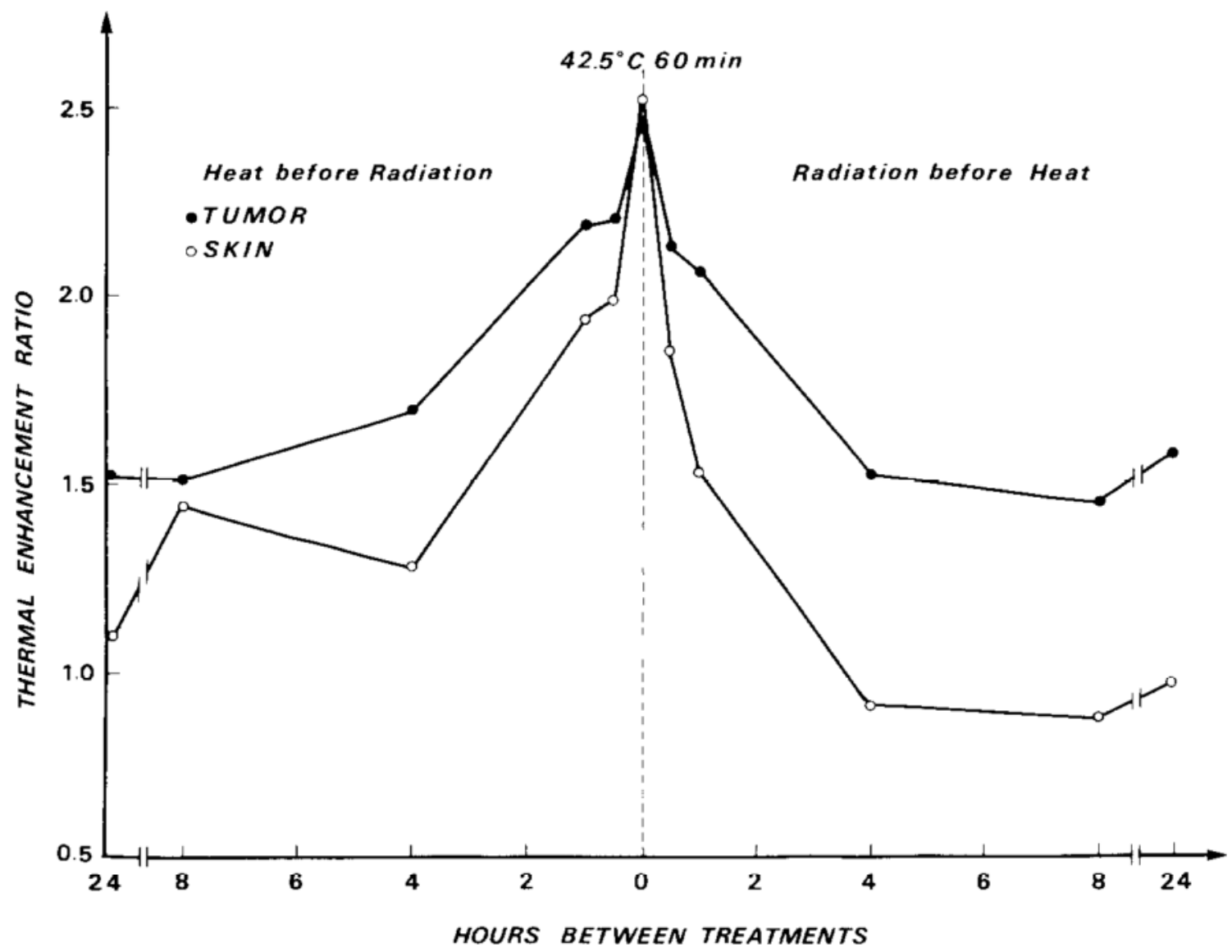

Figure 3: The effectiveness of treatment at different intervals between heat and radiation. It can be seen that the most effective results occur when radiation is applied simultaneously with heat. The figure is replicated from Overgaard $e t . a l^{33}$

\subsection{Gold Nanoparticles}

GNPs have been shown to enhance the effects of ionizing radiation, provide thermal therapy to tissue and aid in the delivery of drugs to certain regions of the body. They have also been shown to be easily produced in large quantities and can be conjugated with many different types of ligands to allow for greater retention in the body and preferential localization inside certain cells. While the capabilities of GNPs in cancer therapy are still being investigated, further research is drawing them closer to their use in the clinical setting. 


\subsubsection{GNPs as a radiation enhancer}

It has been shown in both in vitro and in vivo studies that gold nanoparticles have to ability to enhance the dose of radiation absorbed in tissue. ${ }^{42-48}$ The reason for this is largely due to the high atomic number of the gold. The accumulation of GNPs in a tumor could allow for greater dose enhancement to the tumor. This could result in better tumor treatment, which could necessitate less prescribed radiation dose to the patient.

When a high energy photon (x-ray) is incident on a material, the photon can undergo a variety of interactions. These interactions include, the photoelectric effect, Compton effect and pair production. The probability of these effects occurring depend on their attenuation coefficients. The mass attenuation coefficient for the photoelectric effect is expressed as $\frac{\tau}{\rho}$ and can be said to

have a proportionality of $\frac{\tau}{\rho} \propto \frac{Z^{3}}{(h v)^{3}}$, where $Z$ is the atomic number of the absorbing material and $h v$ is the energy of the incident photon. While this is only an approximation, it shows the strong dependence on the probability of the photoelectric effect occurring and incident photon energy and the type of absorbing material. Using this relationship, one can to see that a greater number of photoelectric events can occur in a high $\mathrm{Z}$ material, like gold $\left(Z_{\mathrm{Au}}=79\right)$ compared to a low $Z$ material, like tissue $\left(Z_{\text {tissue }} \approx 7\right)$. The photoelectric effect can result in the release of a photoelectron, characteristic x-ray or Auger electrons. The charged particles released can proceed to cause DNA strand breaks in cancer cells, resulting in cell death. If a characteristic $\mathrm{X}$-ray is released, it can also go on to produce further interactions with the tissue.

\subsubsection{Dependence on enhancement and energy of radiation}

The energy of the incident photon $(h v)$ can impact the probability of the photoelectric effect occurring. Figure 4 shows that the photoelectric effect dominates at lower energies 
$\left(10^{-3}-10^{0} \mathrm{MeV}\right)$ in gold. At higher energies, Compton scattering is more likely to occur. The relationship between GNP radiosensitization and photon energy can be seen in both Monte Carlo and in vitro studies. ${ }^{49,50}$ A Monte Carlo study by Lechtman et. al. investigated dose enhancement of different types of GNPs using various radiation energies. This study showed that lower energy radiation produced higher dose enhancement compared to higher energy sources. ${ }^{49}$ In vitro studies results have confirmed that the greatest dose enhancement with $\mathrm{kV}$ radiation energies compared to $\mathrm{MV}{ }^{46,51}$

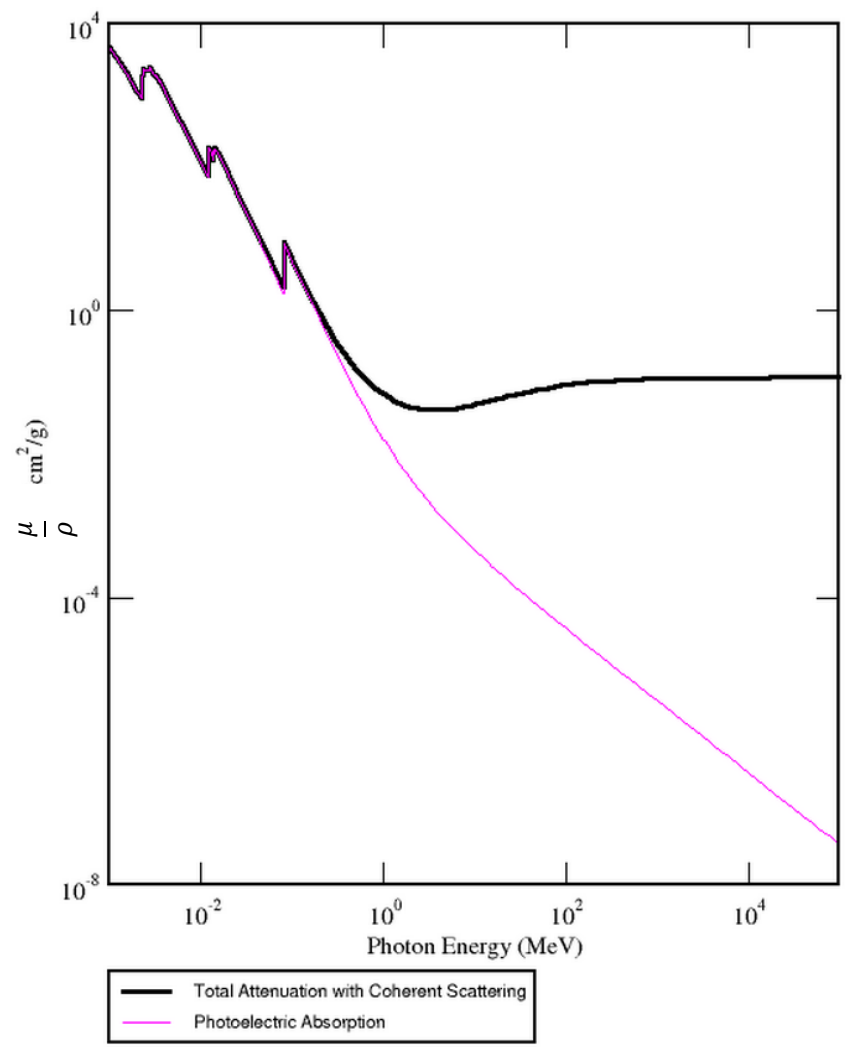

Figure 4: Mass attenuation coefficient indicating photon interactions in gold at photon energies from $10^{-8} \mathrm{MeV}$ to $10^{4} \mathrm{MeV}$. This figure was acquired from the National Institute of Standards and Technology. ${ }^{52}$

When considering the most optimal energy for the largest dose enhancement, it can be seen that photon energies closest to the K, L, M, peaks have the highest probability of the photoelectric 
effect occurring. This is not the most optimal energy to choose however, as the entire energy of the photon will be used to remove the electron from its shell with little to no energy being transferred to the photoelectron.

Letchman's Monte Carlo simulation also touched on this issue by investigating the range of the photoelectrons produced due to photon interactions with GNPs. ${ }^{49}$ It was found that higher photon energies corresponded to larger photoelectron ranges. This photoelectron range is of importance when considering the location of GNPs to achieve greatest radiosensitization. If the electron range is very small, one micron or less, the GNP will need to be located in a very close proximity to the nucleus of the cell to ensure adequate DNA damage. The GNP size will also need to be small enough to prevent internalization of the electrons into the particle. ${ }^{49} \mathrm{~A}$ higher photon energy will correspond to a larger electron range allowing the electrons to travel across cells and reach the cellular DNA. In this case, the location of the GNPs in the cell is of less importance.

\subsubsection{Use of Gold Nanoparticles in Photothermal Therapy}

Gold nanoparticles have the ability to absorb and scatter electromagnetic radiation as a function of wavelength. The ability for GNPs to absorb or scatter this radiation depends on their shape, size and composition. ${ }^{53}$ This allows one to tune the shape and size of the GNP to absorb radiation of a particular wavelength. In the case of using light in photothermal therapy, there is an optical window in the wavelength range of $600 \mathrm{~nm}$ to $1300 \mathrm{~nm}$ which light can penetrate to a reasonable extent (roughly $1.2 \mathrm{~mm}$ at a wavelength of $800 \mathrm{~nm}$ ). ${ }^{54}$ Therefore one would need to use a GNP which can absorb light at a wavelength within this range.

Gold atoms possess an atomic structure where the divide between the valence and conduction band is minimal. This is a common trait between metals, allowing for their common use as 
conductors. ${ }^{55}$ The electrons which exist in the conduction band are not bound to the atom and are free to move about. If a potential were to be applied against a metal, the electrons in the conduction band would flow in a direction and generate a current of electricity.

When a nanoparticle is irradiated with an oscillating electromagnetic field (light), the electrons in the conduction band of the atoms will oscillate coherently with the field (see Figure 5). This effect is known as surface plasmon resonance. The resonance between the electromagnetic field and electrons will allow for the electrons to be displaced away from the nuclei of the atoms. These displaced electrons will feel a restoring force from the positive nucleus due to the Coulomb attraction. ${ }^{56}$ The electrons then transfer their energy to phonons (in picoseconds), in a process called electron-phonon relaxation. Phonon-phonon transfer then occurs which results in distribution of heat to the surroundings. ${ }^{57}$

The extent to which a nanoparticle to absorb and scatter light is expressed by its extinction cross-section $\sigma_{\text {ext }}$ and is represented by $\sigma_{\text {ext }}=\sigma_{\mathrm{abs}}+\sigma_{\mathrm{sca}}$.

The extinction of the light incident on a particle can be measured at various wavelengths. This allows one to determine the wavelengths of light with maximum absorption. In the case of a nanoparticle undergoing SPR, this would be its "surface plasmon peak" and this peak is dependent on the type of nanoparticle, shape and size. The wavelength of the resonance peak is dependent on the real part of the dielectric constant of the nanoparticle. ${ }^{58}$ With a larger negative real dielectric constant, the absorption peak red shifts. ${ }^{59}$

Many in vitro and in vivo studies have used gold nanoparticles and laser light. The majority of these studies use a high power laser to induce a high temperature increase for a short period of time. ${ }^{60-65}$ In a study by Gobin et. al., it was found that targeted nanoshells (EphrinA I conjugated 
with gold nanoshells, EphA2 receptor is overexpressed in PC3 cells) were found to induce greater thermal ablation than PEG-nanoshells. ${ }^{65}$ An in vivo study by Dickerson et. al. found that the direct injection of gold nanorods into a mouse tumor allowed for a greater reduction in tumor growth while requiring less GNPs to be injected and a lower laser power to be used compared to intravenous injection. ${ }^{66}$

GNPs combined with light can also be used to induce hyperthermia in cells or in a tumor. Hauck et. al. investigated the use of plasmonic photothermal therapy (PPTT) to induce hyperthermia in OCI AML3 cells and found that irradiating cells with GNRs and IR light could raise the temperature of the environment to temperatures above $41{ }^{\circ} \mathrm{C}$ and produce greater cell death than cells exposed to IR light without GNRs. ${ }^{67}$

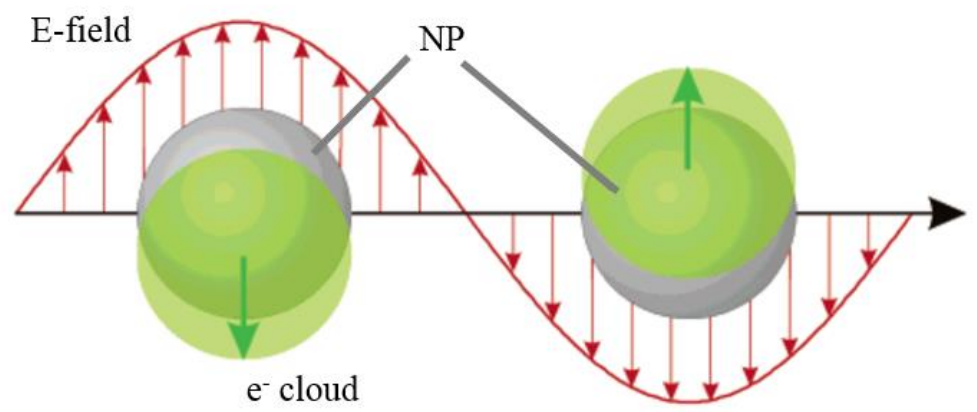

Figure 5: Oscillation of the conduction band electrons against an oscillating electric field. The figure is replicated from Kelly et.al. ${ }^{56}$

In order to ensure successful treatment, the proliferation (growth and spread) of cancer cells should be decreased or stopped while healthy cells remain unharmed. For this to be possible, one must deliver a highly localized radiation and thermal dose distribution. 
It has been widely shown that heating cells to different temperatures can produce different therapeutic effects. Very low temperatures will result in minimal cell death and proliferation, while very high temperatures can result in cell necrosis $\left(+47^{\circ} \mathrm{C}\right) .{ }^{68}$ Cell temperatures in the range of $41{ }^{\circ} \mathrm{C}$ to $45^{\circ} \mathrm{C}$, for extended period of time, mainly result in cell apoptosis, also known as programmed cell death. ${ }^{23,68,69}$ This temperature is commonly used in hyperthermia treatments on tumors as it stops the proliferation of cancer cells while ensuring minimal side effects. ${ }^{23}$

\subsubsection{GNP localization}

To ensure adequate heat distribution and optimal dose enhancement by radiation, the distribution of GNPs in a tumor is critical. Sufficient distribution of GNPs is also one of the most challenging steps in the treatment process.

In vivo studies have shown that there are two popular methods to insert GNPs into a tumor. These are a) intravenous injection (IV) and b) intratumoral (direct) injection. By injecting through IV, one must rely on the GNPs travelling through the circulatory system and settling into the tumor. In order for GNPs to enter a tumor via blood vessels, they must take advantage of the unique properties of a tumor. Tumors are known to possess a leaky and disorganized vasculature, which allows GNPs to enter and remain in the tumor. This effect is known as enhanced permeability and retention (EPR). While the GNPs are in the tumor region, they may be uptaken into the tumor cells via receptor mediated endocytosis. ${ }^{70}$

GNPs can also be directly injected into the tumor site, completely bypassing the blood system. This can allow for a greater number of GNPs reaching the tumor site with less GNPs travelling to other organs of the body, mainly the liver and spleen. An in vivo study by Chattopadhyay et. al. compared the uptake and retention of GNPs in various organs (including 
tumors) using either targeted or non-targeted GNPs delivered by IV or direct injection. ${ }^{71}$ It was found that targeted GNPs delivered to the tumor by direct injection offered the greatest tumor uptake.

\subsubsection{Uptake into cells}

The benefit of targeting GNPs into a cell is the increased probability of the charged particles produced interacting with the DNA of the cell. When a photon interacts with a GNP, it has a greater probability of undergoing a photoelectric or Compton event compared to tissue. The charged particle that is released will have an energy and average range of travel that is related to the energy of the incident photon. High energy photons will produce secondary particles with a larger range than lower energy photons. A Monte Carlo study by Leung et. al. determined the average range of secondary particles produced in GNPs using various photon energies. ${ }^{50}$ Photons with little energy $(50 \mathrm{kVp}$ and $250 \mathrm{kVp})$ produced charged particles with an average range of $2.71 \mu \mathrm{m}$ and $25.7 \mu \mathrm{m}$ respectively in $50 \mathrm{~nm}$ GNPs. This is much smaller than the average range of $1070 \mu \mathrm{m}$ using $6 \mathrm{MV}$ radiation. If a GNP is targeted to allow for increased uptake into the cell and its nucleus, it provides a greater opportunity for the low range secondary electrons to produce more SSB and DSBs in the cell's DNA. Due to the smaller electron range, a targeted GNP will produce a larger dose enhancement when low energy radiation is used compared to high energy. However, targeted GNPs may also provide greater dose enhancement compared to non-targeted GNPs when using higher energy sources where the average charged particle range is greater than the diameter of the cell. This is due to the fact that there is still the chance that low range charges particles could be produced. Furthermore, the Auger electrons have a smaller range of roughly $2 \mu \mathrm{m}$ and the presence of GNPs in the nucleus could allow the Auger electrons to reach the DNA and induce damage. ${ }^{49}$ 
Chithrani et. al. assessed the uptake of different sized GNPs in various cancer cell lines. The uptake of the GNPs was due to receptor mediated endocytosis (RME).$^{70}$ In this study RME relied on the adsorption of serum proteins on the nanoparticle. These serum proteins could then interact with receptors on the cell surface and allow for uptake to occur. ${ }^{72}$ This study also showed that GNP uptake was size and shape dependent. The greatest uptake of GNPs in the cells studied were spherical and $50 \mathrm{~nm}$ in size. It was found that nanoparticles with greater aspect ratio (length to width ratio) had a reduction in cellular uptake. ${ }^{73}$

Another important factor in nanoparticle uptake is the type of coating on the nanoparticle (if any). A number of studies have quantified GNP uptake into different cell types using a variety of proteins, antibodies, peptides and small molecules. The inclusion of these molecules on the surface of the nanoparticle are important to ensure optimal uptake and retention of the GNPs in the tumor. ${ }^{71,72,74}$ The use of a particular targeting ligand can be used to enhance the interaction with an overexpressed receptor on a particular type of cell. ${ }^{75}$ One could also coat the nanoparticle to produce a positively charged surface which has been shown to increase cell membrane interaction and uptake. ${ }^{76}$

\subsection{Antibodies}

Antibodies are an ideal choice to use for nanoparticle targeting as they offer high selectivity and binding affinity. A large contributing factor for this is due to a single antibody molecule possessing two binding sites, increasing the probability of cell membrane interaction. A drawback to this is its cost and potential adverse effects. ${ }^{75}$

The prostate stem cell antigen (PSCA) antibody has been shown to be overexpressed in prostate cancer and marginally expressed in healthy cells. ${ }^{77}$ The PSCA antibody is a 
glycosyl phoshatidylinsitol anchored glycoprotein, indicating that it is anchored to the cell membrane of prostate cancer cells. ${ }^{75}$ By attaching an anti-PSCA antibody to a gold nanoparticle, greater interaction of the nanoparticle with the cell membrane could occur. This could then lead to enhanced nanoparticle uptake in cancer cells and limited uptake in healthy cells.

A study by Wei and Gao used a single chain anti-PSCA antibody for prostate cancer targeting with magnetic nanoparticles. ${ }^{78}$ The uptake into PC 3 cells was enhanced when the nanoparticles were conjugated with anti-PSCA antibody compared to plain nanoparticles. Similar results were seen in a study done by Gao in $2012 .^{79}$

\subsubsection{Uptake into tumors}

Small tumors can rely on a blood supply from the surrounding healthy tissue to provide essential oxygen and nutrients. A larger tumor will require its own vasculature system to provide blood to the interior regions of the tumor. The structure of a tumor is very heterogeneous when compared to healthy tissues. This unorganized vasculature creates areas which are both oxygen deprived (hypoxic) and nutritionally deprived. ${ }^{80} \mathrm{~A}$ lack of oxygen present in the cells makes them more resistant to the effects of radiation due to oxygen's ability to fixate the DNA damage that has been produced by the radiation.

When considering gold nanoparticles and their role in dose enhancement to a tumor, the tumor vascular structure can be both beneficial and a hindrance. While the disorganized and leaky vasculature of the tumor allows for retention of gold nanoparticles in the tumor site alone, the lack of vessels in some parts of the tumor, especially the center, may prevent GNPs from reaching all parts of the tumor. ${ }^{80}$ 
The delivery of GNPs to the tumor is a large hurdle when investigating the clinical ability for these particles to be used in cancer treatment. In vivo studies have investigated the delivery of GNPs to a tumor by either intravenous or intratumoral injection. Intravenous injection relies on the passive transport of GNPs into the tumor site is due to the enhanced permeability and retention effect which is due to the poor vascular structure of the tumor. ${ }^{81,82}$ Goodman et.al studied the penetration and distribution of different sized GNPs in a multicellular spheroid. It was found that large GNPs (100 nm to $200 \mathrm{~nm}$ ) did not distribute well in the spheroid and settled around the periphery. Increased distribution into the center of the tumor was seen in the smaller $20 \mathrm{~nm}$ and $40 \mathrm{~nm}$ GNPs. Finally, it was found that the addition of collagenase treatment increased the distribution of the GNPs into the center of the tumor. ${ }^{83}$ Uniform distribution of GNPs in the tumor site is very important to ensure consistent and localized dose to the tumor.

Intratumoral injection has been shown to deliver more GNPs to the tumor compared to intravenous injection. ${ }^{66}$ A study by Chattopadhyay et. al., showed that intratumoral injection of targeted nanoparticles allowed for the greatest GNP delivery to the tumor compared to nontargeted or intravenous delivery. The enhanced delivery of GNPs to the tumor using direct injection can be seen in Figure $6 .^{71}$ 


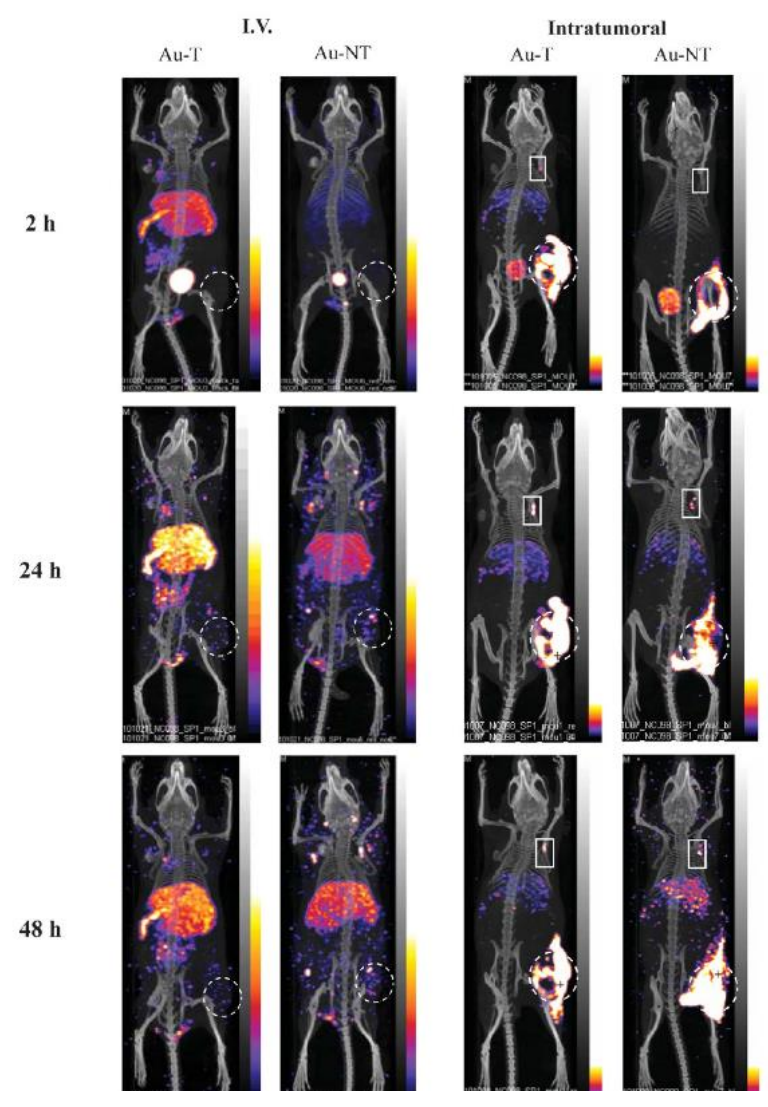

Figure 6: Distribution of GNPs in mice using targeted (T) or non-targeted (NT) GNPs through intravenous or intratumoral injection. The location of the tumor is on the right leg of the mouse. The white regions indicate areas of high GNP localization. It can be seen that the direct injection of either targeted or non-targeted GNPs allow for greater delivery to the tumor. The figure is replicated from Chattopadhyay et.al. ${ }^{71}$

\subsubsection{GNP Removal and Stealth Characteristics}

Gold nanoparticles that have been delivered to the body can be quickly taken up and removed by the reticuloendothelial system (RES) and are largely deposited in the liver and spleen. ${ }^{71,81,84,85}$ Particles with a hydrophobic surface are taken up in greater numbers than those with a hydrophilic surface. This is due to the hydrophilic particles interacting less with macrophages responsible with their removal. Poly-ethylene Glycol (PEG) coated nanoparticles are popular in animal studies as they have greater circulation time in the bloodstream compared to non-PEG nanoparticles. A study by Niidome et. al. found that PEG GNRs had nearly 50\% of 
the injected dose in the blood after 30 minutes, compared to less than 5\% for non-PEG GNRs. ${ }^{85}$ By allowing greater circulation time, more GNPs can enter the tumor by EPR. The downside of a PEG coating on the GNP is the reduction in uptake into the cell due to limited cell membrane interaction. ${ }^{86}$

\subsection{Studies using hyperthermia, GNPs and radiation together.}

As stated previously, numerous studies have been completed which assessed the effectiveness of these treatment methods in conjunction with one another. However, few studies have been performed which use all three treatment methods together. One study which investigated hyperthermia with GNPs and radiation was conducted by Hainfeld et. $a l .{ }^{87}$ Hainfeld found that by using these three treatment methods together in vivo the percentage of mice which survived more than 250 days was $71 \%$ compared to using other treatments ( $0 \%$ to $30 \%$ survival). The effectiveness of the triple treatment method also allowed Hainfeld to apply a reduced radiation dose to the mice, due to dose enhancement from GNPs and hyperthermia.

While this study showed that using all three treatments together can provide a synergistic dose enhancement, there remain a number of elements which need to be investigated. These include quantifying dose enhancement with prostate cancer. Finally, Hainfeld's study heated the tumor region to $48{ }^{\circ} \mathrm{C}$ for $5 \mathrm{~min}$. The temperature is very high compared to hyperthermia temperatures used clinically of $41{ }^{\circ} \mathrm{C}$ to $43^{\circ} \mathrm{C}$. Furthermore, a high temperature of $48{ }^{\circ} \mathrm{C}$ may have included a reduction in blood flow to the tumor which could have decreased the radiation enhancement.

Another study by Buckway et. al. intravenously injected gold nanorods conjugated with Yttrium-90 into mice and exposed the mouse tumors to IR light. This study found that the combination of GNRs, radiation and IR light significantly reduced tumor growth. ${ }^{88}$ Similar 
results were also seen in a study by Diagaradjane who used IR light (exposed for 20 min), gold nanoshells and a $10 \mathrm{~Gy}$ dose of $125 \mathrm{kVp}$ xrays. ${ }^{89}$

While the studies above have shown that the use of GNPs, IR and XRAYs together are an effective therapy, they did not aim for a heating time of $60 \mathrm{~min}$, commonly seen in clinical studies, but opted for heating the tumor for only $10 \mathrm{~min}$ to $20 \mathrm{~min}$. This study's goal was to replicate hyperthermia treatments seen clinically which aim for a temperature of $42.5^{\circ} \mathrm{C}$ to $43{ }^{\circ} \mathrm{C}$ for $60 \mathrm{~min}$.

This in vitro study also allows for analysis of a greater number of conditions to determine the most optimal treatment using NRs, XRAYs and IR. A variety of different IR and XRAY schedules were completed, with different times in between the delivery of IR and XRAYs. Furthermore, the use of targeted (AbNR) and non-targeted (PNR) nanorods were compared on how effective they were at dose enhancement. The AbNRs are conjugated to allow for preferential uptake into prostate cancer cells and the addition of NLS peptides allow for uptake into the cell's nucleus. The variety of conditions employed in this study allowed us to see the most optimal treatment to provide. 


\section{Chapter 2: Methods}

Figure 7 illustrates the experimental setup to assess the dose enhancement when using nanorods, near infrared light and radiation.

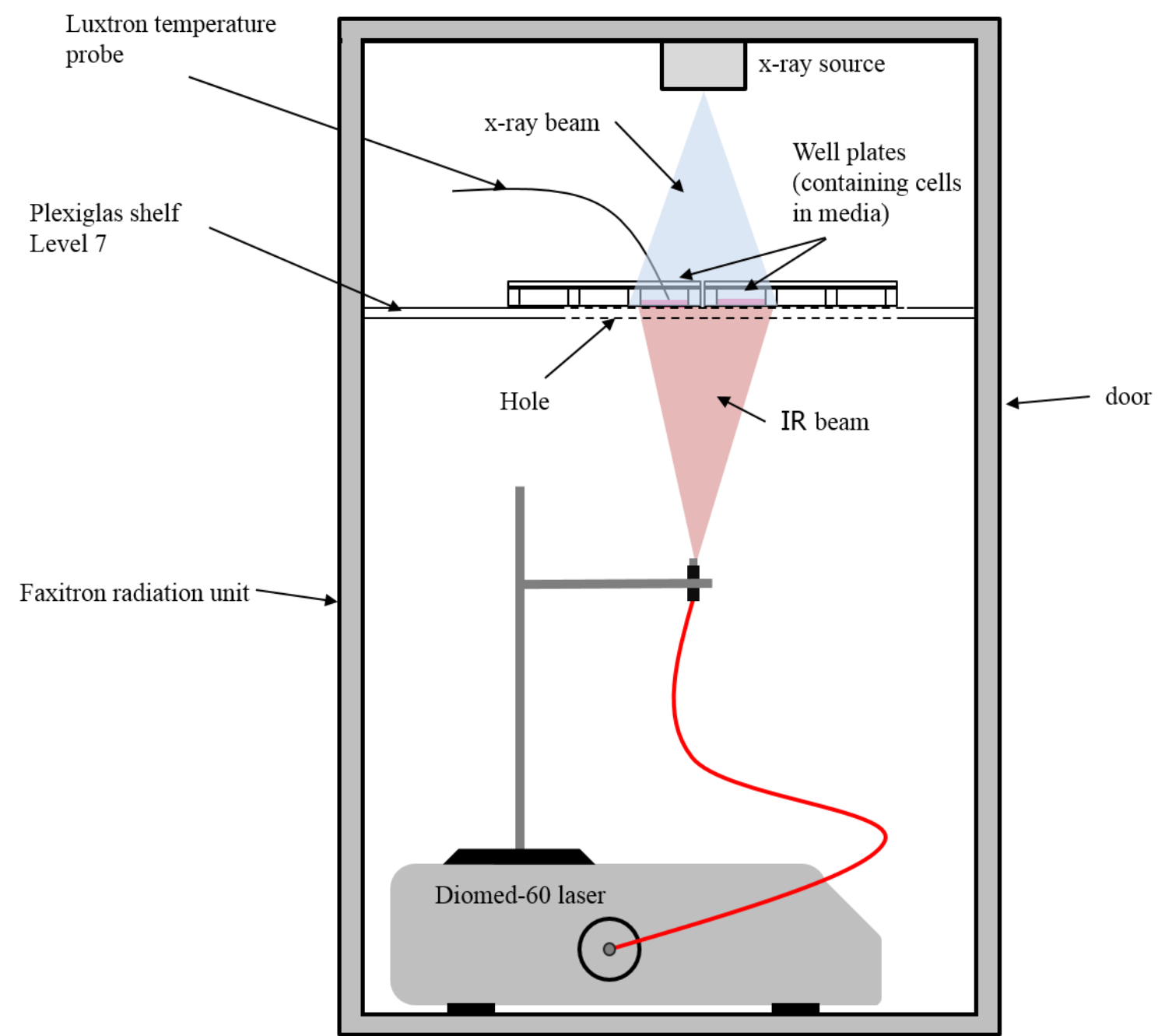

Figure 7: Experimental set up to deliver simultaneous radiation and IR light to the PC3 cells.

The tests that were conducted are listed in Table 1. 
Table 1: List of experiments completed. AbNR and PNR refer to targeted and non-targeted NRs respectively. IR refers to the delivery of $810 \mathrm{~nm}$ light. XRAY $\mathrm{n}$ refers to the delivery of $\mathrm{x}$-rays, where $\boldsymbol{n}$ is the time the $\mathrm{x}$-rays were applied relative to when IR treatment was applied.

\begin{tabular}{|c|c|c|}
\hline Treatment Method & XRAY Dose (Gy) & Trials \\
\hline AbNR/XRAY $Y_{0} / \mathrm{IR}$ & $2,4,8$ & 3 \\
\hline $\mathrm{AbNR} / \mathrm{XRAY}_{+4} / \mathrm{IR}$ & $2,4,8$ & 3 \\
\hline $\mathrm{AbNR} / \mathrm{XRAY}+60 / \mathrm{IR}$ & $2,4,8$ & 3 \\
\hline $\mathrm{AbNR} / \mathrm{XRAY}_{+120} / \mathrm{IR}$ & $2,4,8$ & 3 \\
\hline AbNR/XRAY-60/IR & $2,4,8$ & 3 \\
\hline $\mathrm{AbNR} \mathrm{XRAY}_{-120} / \mathrm{IR}$ & $2,4,8$ & 3 \\
\hline AbNR/IR & 0 & 3 \\
\hline AbNR/XRAY & $2,4,8$ & 3 \\
\hline AbNR & 0 & 3 \\
\hline PNR/XRAY $0 /$ IR & $2,4,8$ & 3 \\
\hline $\mathrm{PNR} / \mathrm{XRAY}+4 / \mathrm{IR}$ & $2,4,8$ & 3 \\
\hline PNR/ IR & 0 & 3 \\
\hline PNR/XRAY & $2,4,8$ & 3 \\
\hline PNR & 0 & 3 \\
\hline $\mathrm{XRAY}_{0} / \mathrm{IR}$ & $2,4,8$ & 3 \\
\hline IR & 0 & 3 \\
\hline XRAY & $2,4,8$ & 3 \\
\hline No Treatment & 0 & 3 \\
\hline
\end{tabular}

Figure 8 shows a timeline of when XRAYs were applied with respect to IR for different treatments. The subscript in XRAY indicates the time in between the delivery of XRAYs and IR. 


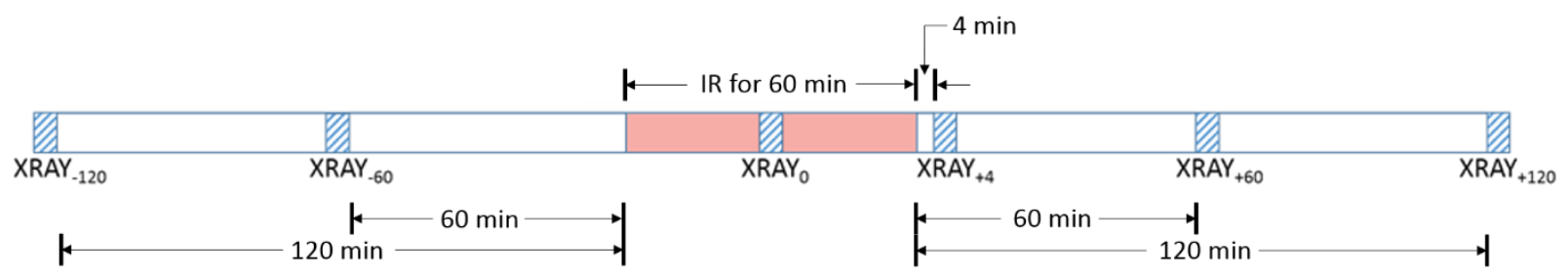

Figure 8: Timeline showing the delivery of XRAYs with respect to IR. The subscript values indicate the amount of time in between the cell's exposure to XRAYs and IR. A negative subscript indicates that XRAYs were given before IR and a positive subscript indicates that XRAYs were given after IR. The exception to this is XRAYo which indicates that the cells were exposed to XRAYs in the middle of IR treatment.

\subsection{In vitro cell model}

An in vitro cell model was used to assess cell survival when exposed to all conditions seen in table 1. A PC3 cell line was cultured in RPMI-1640 culture media supplemented with 10\% fetal bovine serum (FBS) and 5\% penicillin/streptomycin antibiotic. The cells were incubated in a $37{ }^{\circ} \mathrm{C}$ incubator at $5 \% \mathrm{CO}_{2}$. In order to prepare the cells for treatment, they were washed with Phosphate Buffered Saline (PBS) and trypsonized from their culture flask and transferred to 12 well plates at a concentration of $1 \times 10^{5}$ cells $/ \mathrm{mL}$ with $0.5 \mathrm{~mL}$ of media. The cells were exposed to NR, XRAY and IR at various combinations seen in Table 1.

\subsection{Gold nanoparticles}

Gold nanorods (NR), 41 nm in length and $11 \mathrm{~nm}$ in diameter, conjugated with polyethylene glycol (PEG) and suspended in PBS with a concentration of $6.3 \times 10^{13} \mathrm{NR} / \mathrm{mL}$ were used (Nanopartz ${ }^{\mathrm{TM}}$, Inc., Loveland, CO, USA). This size was chosen as it is optically tuned for maximum absorption of the $810 \mathrm{~nm}$ laser light. This wavelength was chosen as it was the wavelength of the available Diomed-60 laser and it offers deeper penetration into tissue than other wavelengths. ${ }^{54}$ The GNRs were added to the cell suspension into a well in a 12 well plate 
at a concentration of $2.0 \times 10^{11} \mathrm{NR} / \mathrm{mL}$ (GNR molar concentration of $3.3 \times 10^{-1} \mathrm{nM}$, gold concentration of $7.0 \times 10^{4} \mathrm{nM}$ ) and incubated for 16 hours before treatment.

Two types of NRs were used in this study. The first NRs were untargeted polyethylene glycol coated nanorods (PNR). The second were targeted NRs (AbNR) which are conjugated with both PSCA antibodies as well as NLS peptides. These Ab ligands can allow for increased uptake of NRs into the PC3 cells and the NLS peptides can allow for NR uptake into the cell's nucleus. ${ }^{45,78}$ The dose enhancement between the use of PNRs and AbNRs were compared to one another.

\subsection{Radiation treatment}

For conditions which required radiation, the cells in the 12 well plate were placed in a radiation unit (Faxitron X-ray Corporation, Lincolnshire, IL, USA) and irradiated using $160 \mathrm{kVp}$ $\mathrm{x}$-rays at a dose rate of $2 \mathrm{~Gy} / \mathrm{min}$. Radiation was given at a dose of $2 \mathrm{~Gy}, 4 \mathrm{~Gy}$ and $8 \mathrm{~Gy}$.

\subsection{Hyperthermia treatment}

The cell+NR+media solution was exposed to $810 \mathrm{~nm}$ laser light by a continuous wave Diomed-60 therapeutic laser (Diomed Ltd., Cambridge, UK) at an intensity of 0.42-0.57 W/ $\mathrm{cm}^{2}$. The power of the laser was modulated to achieve a temperature of $42^{\circ} \mathrm{C}$ to $43^{\circ} \mathrm{C}$ for 60 minutes. A flat tip fiber optic laser fiber, core diameter of $900 \mu \mathrm{m}$ was used to deliver the light to the sample. The tip of the fiber was placed $13 \mathrm{~cm}$ away from the bottom of the 12 well plate. The temperature of the dish was monitored by a Luxtron probe using the Luxtron FOT lab kit (LumaSense, Technologies Inc., Santa Clara, CA, USA).

\subsection{Clonogenic Assay}

Following each test, cell viability was quantified using a colony forming assay. Post treatment, the cells were washed with PBS, trypsonized and centrifuged. The cells were then 
diluted and seeded onto a $60 \mathrm{~mm}$ culture dish and incubated for 7 to 10 days to form colonies. The cells were then stained with Methylene blue and manually counted with an optical microscope. Each experiment was completed three times and the colony assay was done in triplicate.

\subsection{Statistics and Data Analysis}

Cell survival $S$ was calculated by $S \equiv \frac{C}{L E_{\text {control }}}$, where $C$ is the number of colonies counted, $L$ is the number of cell seeded and $E_{\text {control }}$ is the plating efficiency of the untreated control. $P E$ is given by $E_{\text {control }} \equiv \frac{C_{\text {control }}}{L_{\text {control }}}$ where $C_{\text {control }}$ is the number of colonies counted of the control and $L_{\text {control }}$ is the number of cells seeded of the control. Survival fraction $S F$ was plotted for radiation doses of $0 \mathrm{~Gy}, 2 \mathrm{~Gy}, 4 \mathrm{~Gy}$ and $8 \mathrm{~Gy}$ and was fit using the linear quadratic model $S F(D)=\frac{S(D)}{S(0)}=e^{-\left(\alpha D+\beta D^{2}\right)} \cdot{ }^{90}$ Where $S(D)$ is the survival at dose $D, S(0)$ is the survival at 0 Gy and $\alpha$ and $\beta$ are fitting parameters. The data was fit using nonlinear regression, where the $\alpha$ and $\beta$ parameters were determined along with their $95 \%$ confidence intervals and standard error. These parameters were used to compute the dose required to achieve $10 \%$ cell survival and the dose enhancement factor. The survival fractions plotted were expressed as the mean \pm SEM. Where SEM is the standard error of the mean. The error for dose enhancement was determined through propagation of error of the $95 \%$ confidence intervals of the $\alpha$ and $\beta$ parameters.

The synergy of combining NRs with XRAYs and IR was evaluated using the Bliss independence criterion. ${ }^{91}$ The projected additive cell survival was determined by multiplying the cell survival when treatments were completed separately. The combined treatment of NR/XRAY/IR was considered synergistic if the cell survival was lower than the projected additive cell survival. 
An $F$-test was used to determine if the curves are statistically different from one another with a $p$-value less than 0.05 indicating a statistically significant result.

Dose enhancement factors were calculated by dividing the dose $D_{\mathrm{Tr}}$ to achieve $10 \%$ cell survival using a treatment, $\mathrm{Tr}$, by the dose to achieve $10 \%$ cell survival using radiation alone $D_{\text {rad }}$. Dose enhancement factor for $10 \%$ cell survival $\mathrm{DEF}_{10 \%}$ is represented as $\mathrm{DEF}_{10 \%}=\frac{D_{\mathrm{rad}}}{D_{\mathrm{Tr}}}$. If $\mathrm{DEF}_{10 \%}$ is greater than 1 , then treatment $\operatorname{Tr}$ can be said to be more effective at cell killing than using only radiation. 


\section{Chapter 3: Results}

The combination of NR and IR was found to produce temperatures between $42.5^{\circ} \mathrm{C}$ and $43{ }^{\circ} \mathrm{C}$ for 60 minutes. This GNP heat treatment was found to produce a synergistic enhancement of cell death when combined with radiation. The synergistic enhancement of radiation dose was found to be greater when using AbNRs compared to PNRs.

\subsection{PNRs with IR and $160 \mathrm{kVp}$ radiation}

Figure 9 shows a linear quadratic survival plot of cell survival fraction at varying doses of radiation. It can be seen that the combination of PNRs, radiation and IR light produced higher cell death compared to PNRs with radiation or radiation by itself. The dose enhancement ratios for PNR/XRAY, PNR/XRAY ${ }_{0} / \mathrm{IR}$ and $\mathrm{PNR} / \mathrm{XRAY}_{+4} / \mathrm{IR}$ were $1.17 \pm 0.20,1.34 \pm 0.18$ and $1.35 \pm 0.18$ respectively. While the simultaneous delivery of PNR/XRAY/IR provided the larger dose enhancement, the sequential (4 min) combination of PNR/XRAY/IR was not found to be statistically distinguishable from simultaneous. This indicates that the delivery of PNR/XRAY/IR simultaneously does not offer statistically greater dose enhancement than PNR/XRAY/IR applied sequentially where radiation and IR light are applied minutes between one another. All curves were found to be statistically different ( $p<0.05)$, with the exception of $\mathrm{PNR} / \mathrm{XRAY}_{+4} / \mathrm{IR}$ and PNR/XRAY $\mathrm{Y}_{0} / \mathrm{IR}$. 


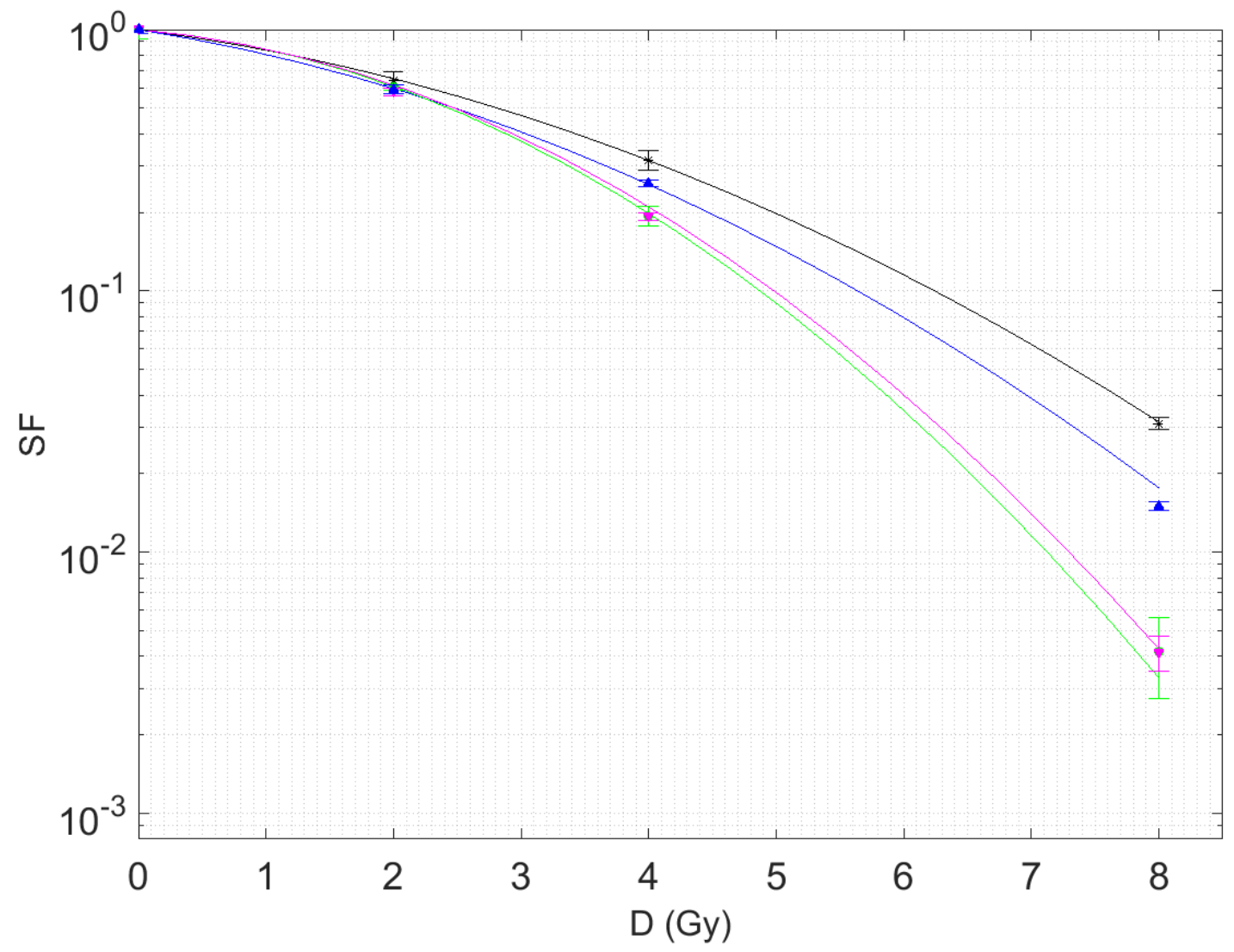

Figure 9: Cell survival fraction using XRAY (*), PNR/XRAY (A), PNR/XRAY+4/IR( $\nabla)$ and PNR/XRAYo/IR (O).

\subsection{AbNRs with IR and 160kVp XRAYs}

Figure 10 displays cell survival curves using XRAYs, AbNR/XRAYs and $\mathrm{AbNR}_{\mathrm{XRAY}}+4 / \mathrm{IR}$ and AbNR/XRAY $0 / \mathrm{IR}$. The use of AbNRs with radiation produced a DEF of 1.45 which is greater than PNRs used with radiation. The dose enhancement ratios for $\mathrm{AbNR}_{\mathrm{XRA}} \mathrm{Y}_{0} / \mathrm{IR}$ and $\mathrm{AbNR} / \mathrm{XRAY}_{+4} / \mathrm{IR}$ were $1.72 \pm 0.26$ and $1.70 \pm 0.26$ respectively. All curves were found to be statistically different from one another $(p<0.05)$, with the exception of $\mathrm{AbNR} / \mathrm{XRAY}+4 / \mathrm{IR}$ and $\mathrm{AbNR} / \mathrm{XRAY}_{0} / \mathrm{IR}$. 


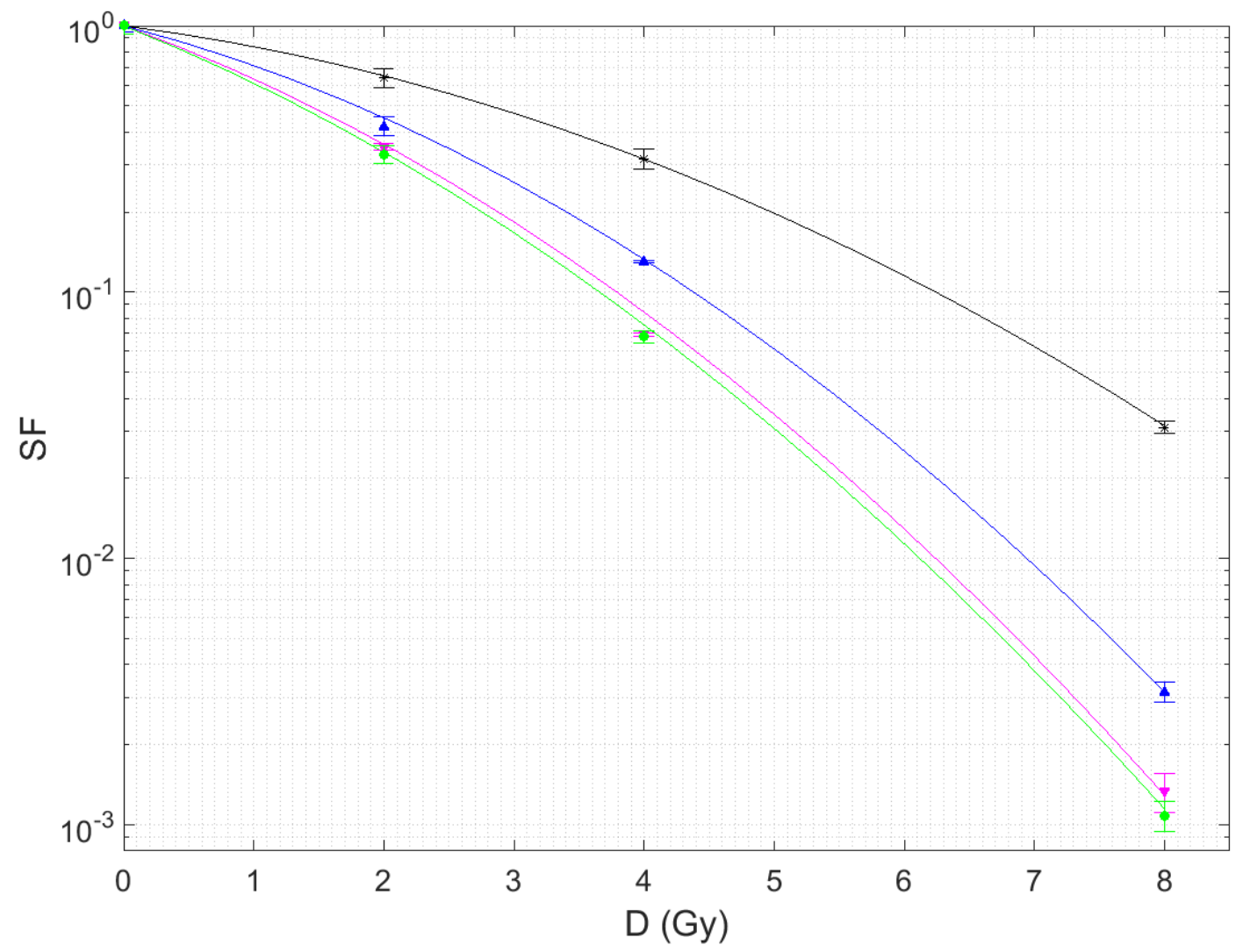

Figure 10: Cell survival curves displaying XRAY alone (*), AbNR/XRAY ( $\Delta$ ), AbNR/XRAY+4/IR ( $\nabla)$ and AbNR/XRAY Y/IR (O).

Figure 11 shows cell survival in treatments that did not involve radiation $S(0)$. It can be seen that alone, neither treatment offers substantial cell death. In the case of NRs alone, the low cell death indicates that the NRs are not cytotoxic to the cells. It can also be seen that heating using IR and either PNRs or AbNRs provided similar cell survival. The cell survival for treatments involving no radiation $S(0)$ were used to normalize the linear quadratic dose curves. 


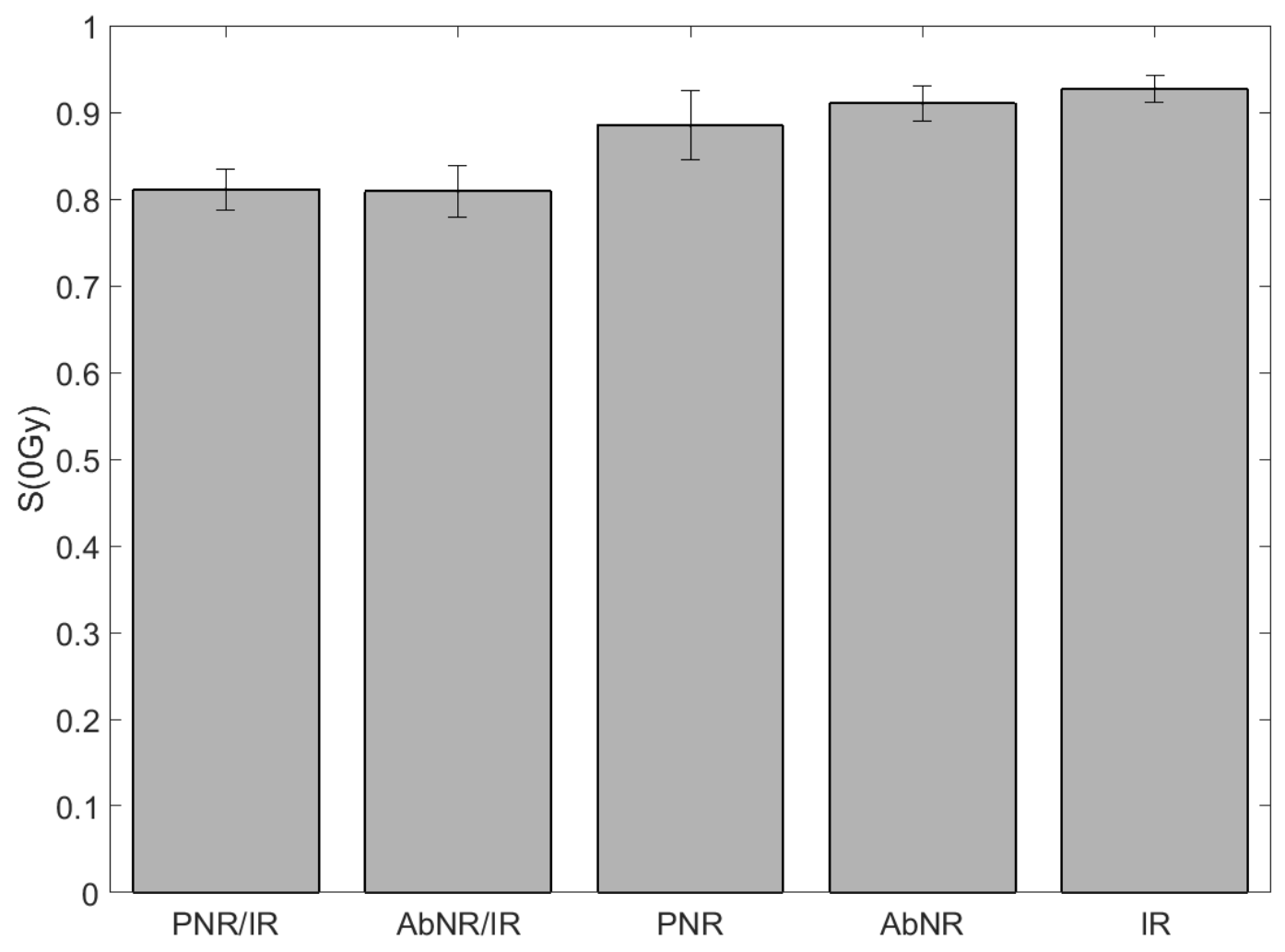

Figure 11: Cell survival for treatments which did not involve radiation.

\subsection{Scheduling of GNPs, radiation and IR light}

When the time between the application of IR light and radiation was increased to one or two hours, there was a noticable decrease in radiation enhancement. Figure 12 displays the decrease in surviving fraction when increasing the time between the application of radiation and IR light with AbNRs. It was also found that the surviving fraction was slightly lower for sequential treatment when AbNR and IR was given before radiation compared to radiation being given before AbNR and IR. However, this was not found to be statisically significant. 


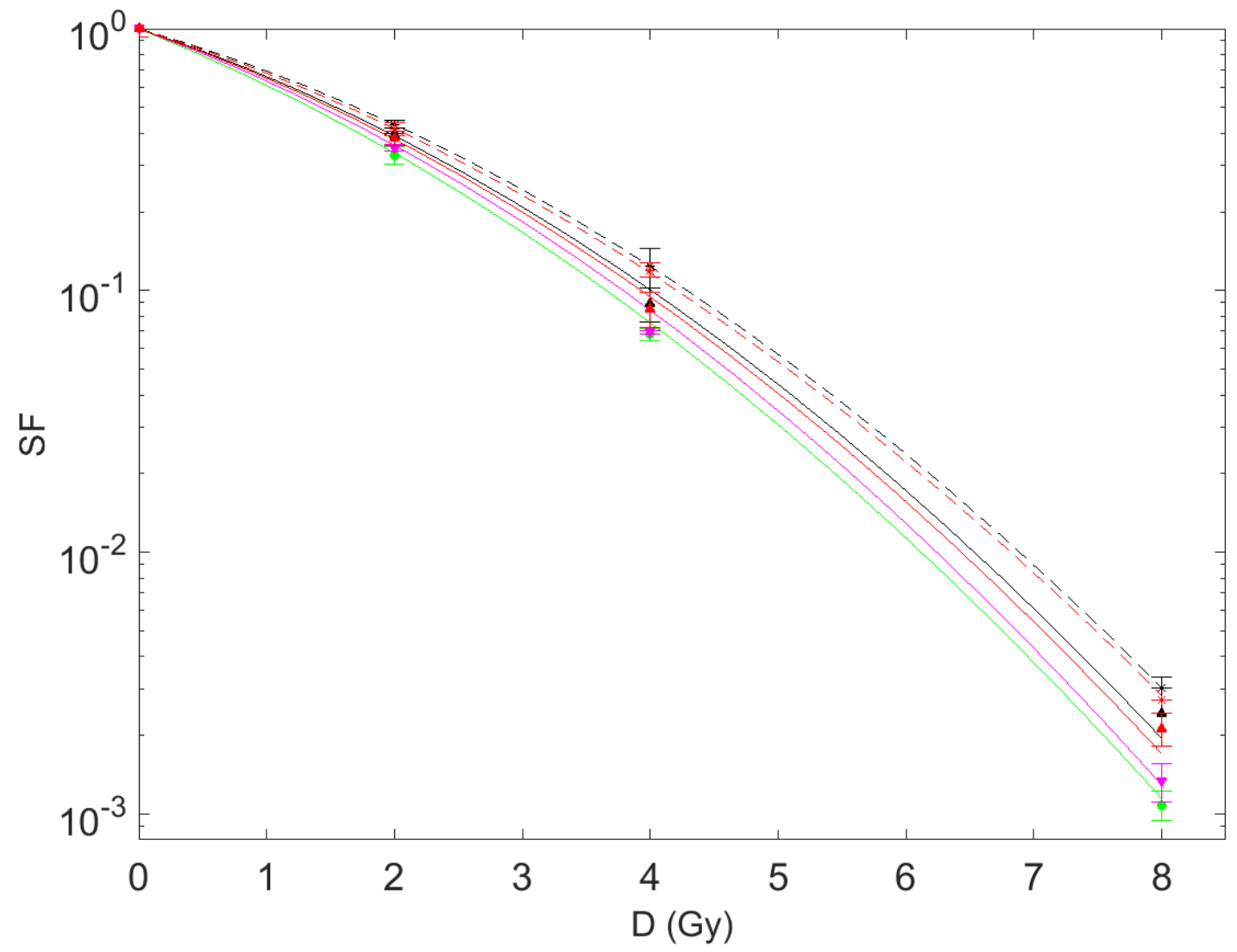

Figure 12: Cell survival curves for AbNR/XRAY-120/IR ( $*$ ), AbNR/XRAY+120/IR ( * $)$,

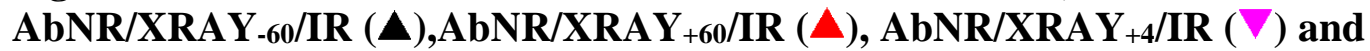
AbNR/XRAYo/IR (O).

\subsection{Synergism}

Figures 13 and 14 display the projected additive curves using untargeted and targeted NRs respectively. These curves were produced by calculating the additive survival fraction for radiation doses of $0,2,4$ and 8 Gy using the Bliss criterion..${ }^{91}$ Since this study employs three types of treatments: GNPs, radiation and IR light, there are a number of potential additive survival curves to compare with the experimental results. The experimental cell survival curves for both PNRs and AbNRs show lower surviving fraction than the projected additive curves and 
are statistically different from one another $p<0.05$. This larger cell death means that the simultaneous delivery of NR/XRAY/IR provides synergistic cell death.

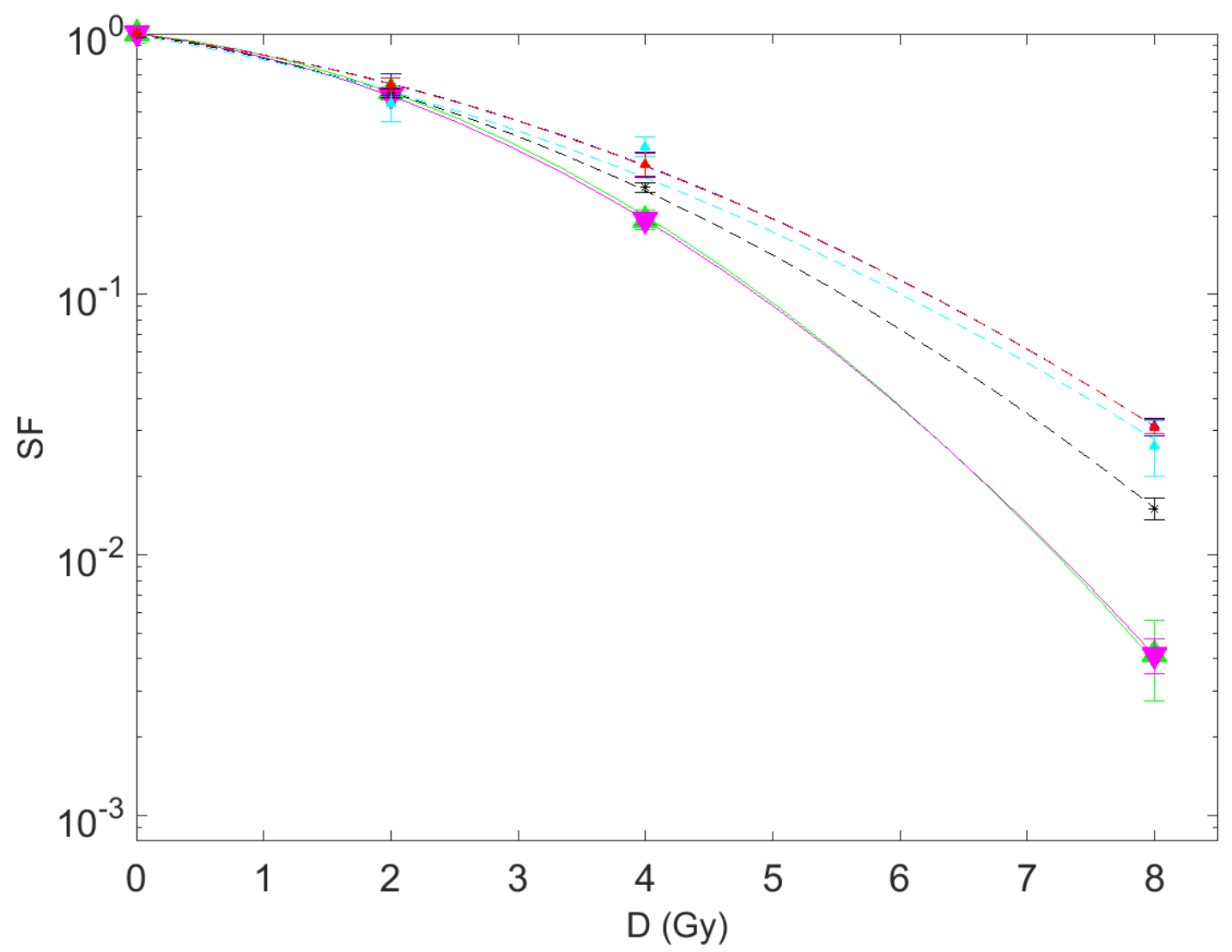

Figure 13: Survival curves comparing experimental results and curves which act additively. The curves PNR/IR + XRAY $(\Delta), \operatorname{PNR} / \mathrm{XRAY}+\operatorname{IR}(*)$, PNR + XRAY/IR ( $\triangle$ ) and PNR + XRAY + IR $(\Delta)$ are statistically different from the experimental curves PNR/XRAY $+4 / I R(\nabla)$ and PNR/XRAY $0 / I R(\Delta) . \quad(p<0.05)$. 


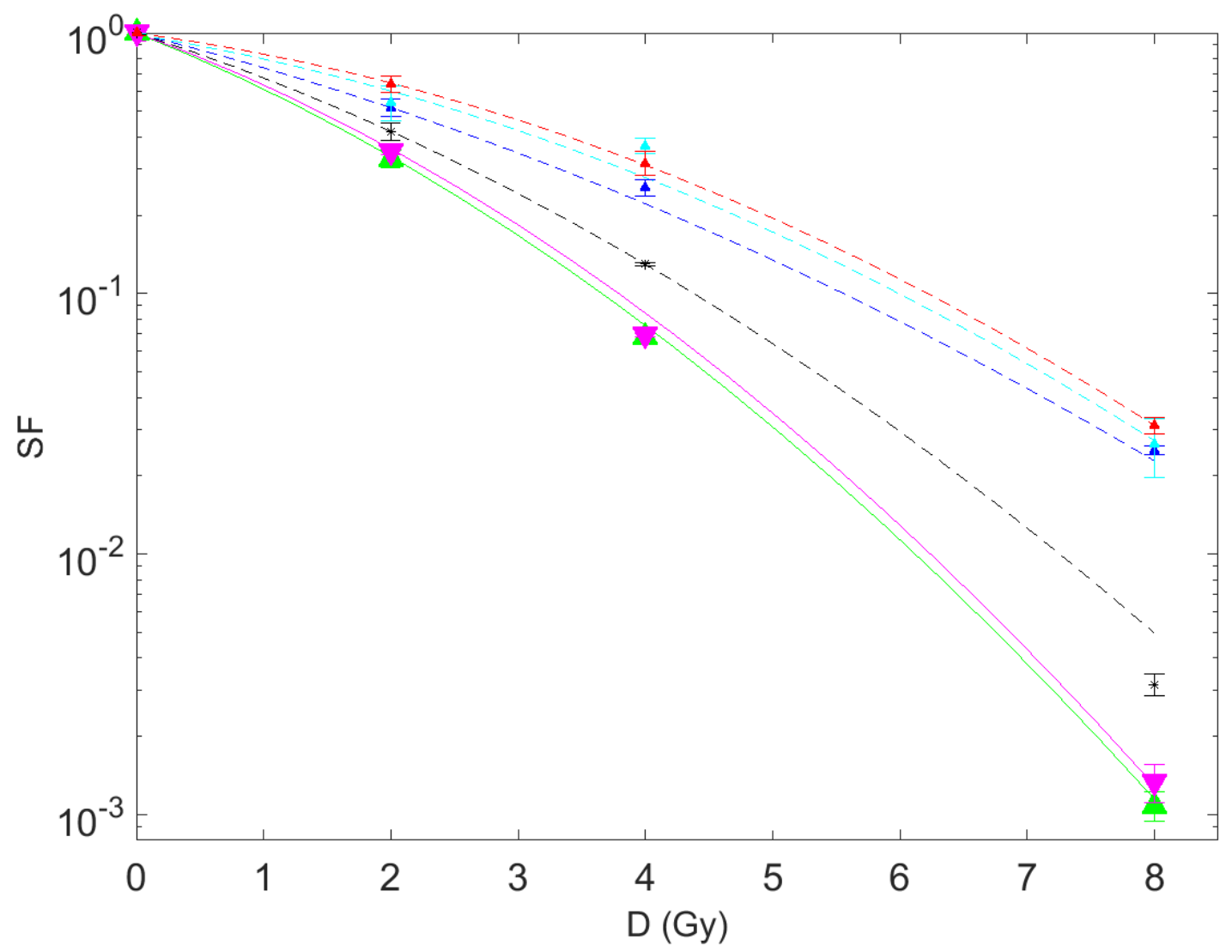

Figure 14: Survival curves comparing experimental results and curves which act additively. The curves AbNR/IR + XRAY( $\triangle)$, AbNR/XRAY + IR (*), AbNR + XRAY/IR $(\triangle)$ and AbNR + XRAY + IR ( $\triangle)$ are statistically different from the experimental curves AbNR/XRAY $+4 / \operatorname{IR}(\nabla)$ and AbNR/XRAY $\mathbf{X}_{0} / \mathbf{I R}(\Delta)(p<0.05)$.

\subsection{Dose enhancement factors}

Figure 15 displays dose enhancement factors for all combination treatments with radiation as seen in table 1. The use of targeted AbNRs had higher dose enhancement compared to the untargeted PNRs. It can also be seen that the addition of IR to NRs and XRAY increases dose enhancement. The highest dose enhancement is seen with the simultaneous application of AbNRs, XRAYs and IR light. 


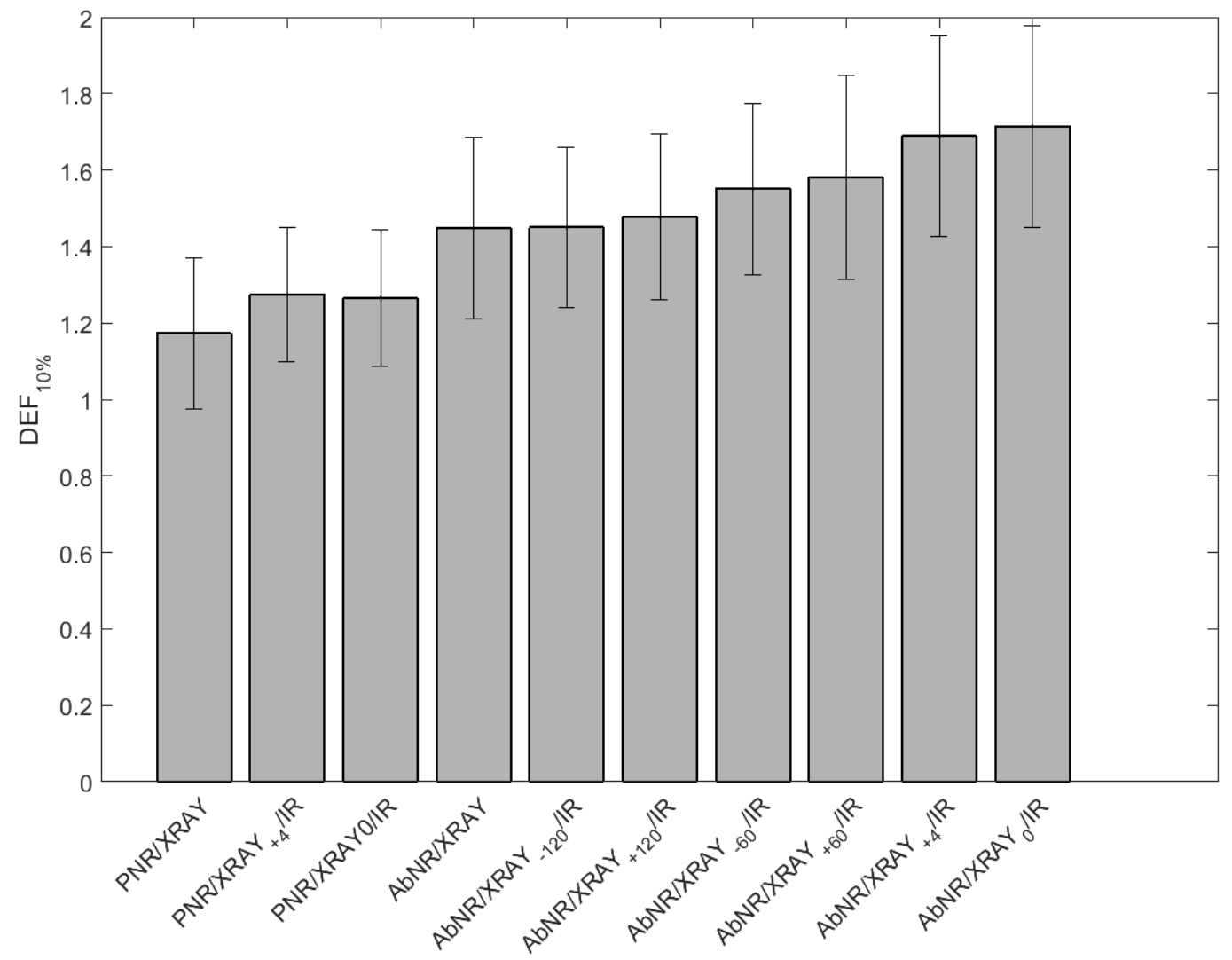

Figure 15: DEFs for various treatments. 


\section{Chapter 4: Discussion}

The combination of targeted gold nanoparticles and near-infrared light has shown to produce a synergistic enhancement of radiation dose in PC3 prostate cancer cells. There are two synergies which act when all three treatments are combined. The first synergy is the increased production of charged particles due to the high probability of radiation interacting with GNPs. The second is the surface plasmon resonance induced hyperthermia when GNPs are combined with IR light. Hyperthermia has been shown to produce a synergistic radiation dose enhancement in vitro, due to the inhibition of DNA double strand break repair. ${ }^{28}$

The greatest dose enhancement ratio was found with the use of targeted gold nanoparticles, which produced a DEF of 1.45 and 1.72 for AbNR/XRAY and AbNR/XRAY/IR respectively. These DEF values were greater than those produced by PNRs which produced DEF values of 1.17 and 1.27 respectively. The reason for the greater DEF when using AbNRs is most likely due to increased uptake of the AbNRs into the cell and the cell's nucleus allowing for the low range electrons to reach the cell's DNA and induce strand breaks. Low energy electrons emitted from a GNP that is not inside a cell's nucleus may not have enough range to reach the DNA to induce damage.

\subsection{GNP radiation enhancement}

\subsubsection{Comparison of DEF using GNPs and Radiation}

Many studies which analyze DEF using GNPs and radiation compare the dose required to achieve $10 \%$ cell survival using radiation alone and GNPs combined with radiation. ${ }^{43,46,92}$ The ratio of these two doses corresponded to the dose enhancement factor. A study by 
Chithrani et. al. showed that a high DEF of 1.66 was achieved in HeLa cells using bare GNPs at a concentration of $7 \times 10^{9} \mathrm{GNP} / \mathrm{mL} \cdot{ }^{73}$ Other studies have investigated GNP DEF with various other cells lines. These studies indicate that some cell lines respond better to GNPs with radiation than others. Jain et. al. compared DEF using breast cancer and prostate cancer cell lines. ${ }^{51}$ It was found that prostate cancer cells had DEFs of 0.97-1.08 while breast cancer cells had a DEF of 1.41. A study using 30nm PEG GNPs in PC3 cells with 300kVp radiation achieved a DEF of $1.15 .{ }^{93}$ This low dose enhancement is most likely due to the decreased uptake of GNPs into the cell due to the PEG coating. A study by Arnida et. al. has shown that PEG GNPs have reduced uptake into the cell compared to plain GNPs.$^{86}$ This may be due to the inhibition of the GNP interacting with the cell membrane and allowing for receptor mediated endocytosis.

\subsubsection{Dependence of DEF and GNP Localization in the Cell}

The higher dose enhancement seen with the use of AbNRs compared to PNRs is most likely due to the increased uptake of AbNRs into the cells and the cell's nucleus. A study by Ling et. al. showed that magnetic nanoparticles conjugated with Anti-PSCA antibodies allowed for approximately two times more nanoparticle uptake into PC3 cells compared to PEGylated nanoparticles. ${ }^{78}$ An in vitro study by Yang et. al. showed that the combination of GNPs with NLS peptides allowed for a roughly 4-fold decrease in cell survival compared to GNPs without NLS peptides. ${ }^{45}$ It has also been widely shown that PEGylated GNPs have significantly less uptake into cells compared to plain or targeted GNPs. ${ }^{86,94} \mathrm{~A}$ major drawback to the clinical potential of GNPs is the inability to deliver an adequate amount of GNPs to the tumor, to provide a therapeutic effect. ${ }^{95}$ The increased uptake of targeted GNPs into cancer cells could allow for more DNA double and single strand breaks. 


\subsection{Hyperthermia}

Hyperthermia has been shown clinically to provide greater tumor control when combined with radiation versus using radiation alone..$^{21,25,26,37,40}$ This was also shown in various in vitro and in vivo studies. ${ }^{27,33}$ Ryu et. al. investigated the use of hyperthermia in prostate cancer cells (PC3 and DU-145) and found that prostate cancer cells were more sensitive to heat than other cells lines. ${ }^{20}$ While hyperthermia has the ability to induce cell death via apoptosis, that alone is not sufficient to provide enough cell death to allow for tumor control. I found that hyperthermia induced by PNR/IR and AbNR/IR resulted in $81.11 \%$ and $80.90 \%$ cell survival respectively. However, when hyperthermia was combined with radiation, a synergistic enhancement was seen. Ryu showed that by combining hyperthermia $\left(41{ }^{\circ} \mathrm{C}\right.$ for $\left.120 \mathrm{~min}\right)$ and ${ }^{137} \mathrm{Cs}$, a thermal enhancement ratio (TER) of 1.4 could be achieved.$^{20}$ This synergistic enhancement of radiation dose is due to the lack of repair of DNA strand breaks. When a cell is exposed to radiation, there are a number of DNA single and double strand breaks. If this cell is also exposed to hyperthermia, inhibition of repair of the sublethal damage caused by the radiation can occur. ${ }^{28}$

\subsection{Production of Heat using GNPs and IR light}

The most common methods to raise the temperature of tissue to achieve hyperthermia is through the use of RF or microwave radiation. ${ }^{23}$ On the other hand the use of GNPs with IR light provides the ability to apply conformal heating. Gold nanorods are an optimal choice for use in thermal therapy with IR light. This is due to their peak absorption in the IR range. The GNRs are able to absorb the IR light and emit the energy as heat. ${ }^{59,66}$ This will result in local heating only in areas where GNRs are present, resulting in minimal heating to tissue without GNRs. Their radiation enhancing capabilities furthers the dose enhancing effect that they can provide. 


\subsection{Hyperthermia and radiation scheduling vs dose enhancement}

This study and others by Overgaard have shown that by applying hyperthermia and radiation together simultaneously provides greater dose enhancement than by applying them sequentially. ${ }^{33}$ These studies also show that as the time between the application of hyperthermia and radiation increases, the dose enhancement decreases.

If radiation is delivered and followed by hyperthermia a few hours later, there is a greater opportunity for the sublethal damage caused by the radiation to be repaired. ${ }^{1}$ In the case where hyperthermia is applied a few hours before radiation, it is possible that the inhibition of DNA repair caused by hyperthermia will not be as prominent compared to the simultaneous delivery of both modalities. While it was found that radiation applied in the middle of heat treatment provided the greatest dose enhancement, it was not significantly different than dose enhancement when radiation immediately followed heating.

The larger dose enhancement seen in simultaneous heating and radiation compared to sequential is much more pronounced in vivo than in vitro. This is most likely due to the increase in blood flow and oxygenation of the hypoxic tumors. The radiation enhancement offered by oxygen can only act for a brief period of time. If the heating is stopped and the tissue is allowed to cool, there may be a reduction in blood flow and lower enhancement from oxygen. This was not seen in this study as all samples had the same access to oxygen and none were in hypoxic conditions.

Even though it has been shown biologically that simultaneous hyperthermia and radiation provides the highest dose enhancement, it may be difficult to apply clinically, especially for deep seated tumors. In the case of prostate cancer, one would need to place the heating equipment interstitially which may not be appealing due to the invasive nature of the procedure. 


\subsection{GNP location in the tumor}

Gold nanoparticles have been shown to be quite effective at the cellular level in vitro. While these studies are essential in investigating the initial impact of a treatment modality on the cell, their effectiveness may not correlate when moving to more complex systems such as animals or humans. The largest uncertainty in research involving GNPs today is their ability to be delivered to the tumor in a high enough concentration while limiting GNP retention in other organs of the body such as the kidney, spleen and liver. In vivo studies have investigated the

distribution of GNPs inside a body. ${ }^{81,85} \mathrm{~A}$ study by Chattopadhyay et.al. showed that a large portion of the GNPs that are delivered by IV end up in the spleen, liver and kidney 48 hours after injection. Only $2.23 \%$ of the injected dose ended up in the tumor. ${ }^{71}$ An alternative to the intravenous injection of GNPs, where one relies on enhanced permeability and retention brought upon by the disorganized and leaky vasculature of the tumor, is the use of a direct injection of GNPs into the tumor. Chattopadhyay et.al. found that directly injecting GNPs that are conjugated with a targeting antibody could allow for the greatest GNP uptake into the tumor versus intravenous injection or non-targeted GNPs. Directly injecting targeted GNPs allowed for 30\% of the injected dose to reach the tumor versus approximately $1 \%$ using intravenous. ${ }^{71}$ By directly injecting the GNPs into the tumor, there is less likely a chance that the GNPs can be carried away to other organs. Furthermore, by conjugating the GNPs with targeting ligands, there is a greater probability that the GNPs can be uptaken into the cells in the tumor further retaining them and allowing for greater radiation dose enhancement. 


\section{Chapter 5: Conclusions and Future}

\section{Work}

\subsection{Conclusions}

It has been shown that the delivery of $\mathrm{x}$-rays, near infrared light and gold nanorods provides synergistic radiation enhancement provided that the delivery of $\mathrm{x}$-rays and near infrared light are delivered simultaneously together or immediately after one another. As the time between the delivery of $\mathrm{x}$-rays and IR increases, the radiation enhancement decreases. It has also been shown that gold nanorods conjugated with anti-PSCA antibodies + NLS peptides had higher radiation enhancement compared to PEGylated gold nanorods. This is likely due to the increased uptake of AbNRs into the cell and the cell's nucleus compared to PNRs.

\subsection{Clinical Potential and Future work}

The clinical potential of combining NRs with x-rays and IR would be most practical as a salvage therapy for previously failed radiation treatment. The combination treatment could allow for effective treatment of the recurrent tumor with less prescribed radiation dose. This could result in fewer side effects from the radiation treatment. The most practical way to deliver this treatment is with the use of high dose rate (HDR) brachytherapy. HDR uses an Ir-192 sources which emits an average energy of $380 \mathrm{keV}$. This source is interstitially inserted into the patient's prostate to deliver a conformal and high dose to the prostate. Since Ir-192 is delivered to the prostate interstitially, the NRs could also be directly injected into the tumor to ensure optimal delivery of NRs. The IR could also be inserted interstitially using the same method as inserting 
the Ir-192 sources. This could allow for less time between the delivery of radiation and heating. A phase 1 clinical study by Prionas $e t$. al. provided simultaneous hyperthermia and HDR radiation treatment. The interstitial hyperthermia was delivered via microwave radiation. A benefit of using this treatment with HDR brachytherapy is the possibility of using the same entry points into the prostate for heating as for the delivery of the Ir-192 sources. ${ }^{21}$

Moving forward with this project, more work is needed to assess dose enhancement using a higher energy source. In this case, the only practical radiation source that was available had a maximum energy of $160 \mathrm{keV}$. In order to realistically assess the clinical potential of this treatment, an Ir-192 source should be used. Cell uptake analysis must also be completed to evaluate how effective the targeted AbNRs are at cell uptake compared to the untargeted PNRs. 


\section{References}

1. Hall EJ, Giaccia AJ. Radiobiology for the Radiologist. 2 nd. Philadelphia: Lippincott Williams and Wilkins; 2006.

2. Attix F. Introduction to Radiological Physics and Radiation Dosimetry. Wiley; 1986.

3. Podgorsak E. Radiation Physics for Medical Physicists. 2nd ed. Springer; 2010.

4. $\quad$ Alpen EL. Radiation Biophysics. 2 nd. San Diego: Academic Press; 1998.

5. Chaterjee A, Holley WR. Computer simulation of initial events in the biochemical mechanisms of DNA damage. Adv Radiat Biol. 1993;17:181-226.

6. Jelveh S, Chithrani DB. Gold nanostructures as a platform for combinational therapy in future cancer therapeutics. Cancers (Basel). 2011;3(1):1081-1110. doi:10.3390/cancers3011081.

7. Dewhirst MW, Kimura H, Rehmus SWE, Braun RD, Papahadjopoulos D, Hong K. Microvascular studies on the origins of perfusion-limited hypoxia. Br J Cancer. 1996;74:S247-S251.

8. Janssen HLK, Haustermans KMG, Sprong D, et al. HIF-1A, pimonidazole, and iododeoxyur- idine to estimate hypoxia and perfusion in human head-and-neck tumors. Int J Radiat Oncol Biol Phys. 2002;54(5):1537-1549.

9. Vaupel P, Kallinowski F, Okunieff P. Review Blood Flow , Oxygen and Nutrient Supply, and Metabolic Microenvironment Human Tumors : A Review. Cancer Res. 1989;49:64496465 .

10. van der Zee J. Heating the patient: a promising approach? Ann Oncol. 2002;13(8):11731184. doi:10.1093/annonc/mdf280.

11. Gerweck LE, Nygaard TG, Burleft M. Response of Cells to Hyperthermia under Acute and Chronic Hypoxic. Cancer Res. 1979;39(March):966-972.

12. Dewey WC, Thrall DE, Gillette EL. Hyperthermia and radiation - a selective thermal effect on chronically hypoxic tumor cells in vivo. Int J Radiat Oncol Biol Phys. 1977;2(1):99-103.

13. Sapareto SA, Hopwood LE, Dewey WC, Raju MR, Gray JW. Effects of hyperthermia on survival and progression of chinese hamster ovary cells. Cancer Res. 1978;38(February):393.

14. Overgaard J. Effect of local hyperthermia on the acute toxicity of misonidazole in mice. Br J Cancer. 1979;39:96-98.

15. Sapareto SA, Dewey WC. Thermal dose determination in cancer therapy. Int J Radiat Oncol Biol Phys. 1984;10(February):787-800.

16. Dewhirst MW, Vujaskovic Z, Jones E, Thrall D. Re-setting the biologic rationale for 
thermal therapy. Int J Hyperthermia. 2005;21(8):779-790.

doi: $10.1080 / 02656730500271668$.

17. Dunlop PRC, Hand JW, Dickinson RJ, Field SB. An assessment of local hyperthermia in clinical practice. Int J Hyperth. 1986;2(1):39-50.

18. Anscher M, Samulski T, Dodge R, Prosnitz L, Dewhirst M. Combined external beam irradiation and external regional hyperthermia for locally advanced adenocarcinoma of the prostate. Int J Radiat Oncol Biol Phys. 1997;37(5):1059-1065.

19. van Vulpen M, Raaymakers BW, de Leeuw A a C, et al. Prostate perfusion in patients with locally advanced prostate carcinoma treated with different hyperthermia techniques. J Urol. 2002;168(4 Pt 1):1597-1602. doi:10.1097/01.ju.0000030155.67888.5b.

20. Ryu S, Brown S, Kim S-H, Khil M, Kim JH. Preferential radiosensitization of human prostatic carcinoma cells by mild hyperthermia. Int J Radiat Oncol Biol Phys. 1996;34(1):133-138.

21. Prionas S, Knapp DS, Goffinet DR, Ben-Yosef R, Fessenden P, Bagshaw MA. Thermometry of interstitial hyperthermia given as an adjuvant to brachytherapy for the treatment of carcinoma of the prostate. Int J Radiat Oncol Biol Phys. 1993;28:151-162.

22. Algan O, Fosmire H, Hynynen K, et al. External beam radiotherapy and hyperthermia in the treatment of patients with locally advanced prostate carinoma. Cancer. 2000;89(2):399-403.

23. Hildebrandt $\mathrm{B}$, Wust $\mathrm{P}$, Ahlers $\mathrm{O}$, et al. The cellular and molecular basis of hyperthermia. Crit Rev Oncol Hematol. 2002;43:33-56.

24. Arcangeli G, Cividalli A, Nervi C, Creton G. Tumor control and therapeutic gain with different schedules of combined radiotherapy and local external hyperthermia in human caner. Int J Radiat Oncol Biol Phys. 1983;9:1125-1134.

25. Overgaard J, Gonzalez Gonzalez D, Hulshof $\mathrm{MCCH}$, et al. Hyperthermia as an adjuvant to radiation therapy of recurrent or metastatic malignant melanoma. A multicentre randomized trial by the European Society for Hyperthermic Oncology. 1996. Int J Hyperthermia. 2009;25(5):323-334. doi:10.1080/02656730903091986.

26. Vernon CC, Hand JW, Field SB, et al. Radiotherapy with or without hyperthermia in the treatment of superfcial localized breast cancer: results from five randomized controlled trials. Int J Radiat Oncol Biol Phys. 1996;35(4):731-744.

27. Horsman MR, Overgaard J. Hyperthermia: a potent enhancer of radiotherapy. Clin Oncol (R Coll Radiol). 2007;19(6):418-426. doi:10.1016/j.clon.2007.03.015.

28. Kampinga HH, Dikomey E. Review Hyperthermic radiosensitization : mode of action and clinical relevance. Int J Radiat Biol. 2001;77(4):399-408.

29. Song CW, Park H, Griffin RJ, Res R. Improvement of tumor oxygenation by mild hyperthermia. Radiat Res. 2001;155(4):515-528.

30. Griffin RJ, Dings RPM, Jamshidi-Parsian A, Song CW. Mild temperature hyperthermia and radiation therapy: role of tumour vascular thermotolerance and relevant physiological 
factors. Int J Hyperthermia. 2010;26(3):256-263. doi:10.3109/02656730903453546.

31. Horsman MR, Overgaard J. Hot Topic: Can mild hyperthermia improve tumour oxygenation? Int J Hyperth. 1997;13(2):141-147. doi:10.3109/02656739709012378.

32. Gerweck LE, Gillette EL, Dewey WC. Effect of Heat and Radiation on Synchronous Chinese Hamster Cells : Killing and Repair. Radiat Res. 1975;64(3):611-623.

33. Overgaard J. Simultaneous and sequential hyperthermia and radiation treatment of an experimental tumor and its surrounding normal tissue in vivo. Int J Radiat Oncol Biol Phys. 1980;6:1507-1517.

34. Sapareto SA, Raaphorst PG, Dewey WC. Cell killing and the sequencing of hyperthermia and radiation. Int J Radiat Oncol Biol Phys. 1979;5:343-347.

35. Meyer KR, Hopwood LE, Gillette EL. The Response of Mouse Adenocarcinoma Cells to Hyperthermia and Irradiation. Radiat Res. 1979;78:98-107.

36. Joshij DS, Barendsen GW, Schueren E. Thermal enhancement of the effectiveness of gamma radiation for induction of reproductive death in cultured mammalian cells. Int $J$ Radiat Biol. 1978;34(3):233-234.

37. van der Zee J, González D, van Rhoon GC, van Dijk JD, van Putten WL, Hart AA. Comparison of radiotherapy alone with radiotherapy plus hyperthermia in locally advanced pelvic tumours: a prospective, randomised, multicentre trial. Lancet. 2000;355(9210):1119-1125. doi:10.1016/S0140-6736(00)02059-6.

38. Valdagni R, Amichetti M. Report of long-term follow-up in a randomized trial comparing radiation therapy and radiation therapy plus hyperthermia to meta- static lymphnodes in stage IV head and neck patients. Int J Radiat Oncol Biol Phys. 1993;28(July):163-169.

39. Datta NR, Bose AK, Kapoor HK, Gupta S. Head and neck cancers: Results of thermoradiotherapy versus radiotherapy. Int J Hyperth. 1990;6(3):479-486. doi:10.3109/02656739009140944.

40. Hurwitz MD, Hansen JL, Prokopios-Davos S, et al. Hyperthermia combined with radiation for the treatment of locally advanced prostate cancer: long-term results from Dana-Farber Cancer Institute study 94-153. Cancer. 2011;117(3):510-516. doi:10.1002/cncr.25619.

41. Overgaard J, Gonzalez D, Hulshof MCCM, Arcangeli G, Mella O, Bentzen SM. Randomised trial of hyperthermia as adjuvant to recurrent or metastatic malignant melanoma radiotherapy for recurrent or metastatic malignant melanoma. Eur Soc Hyperthermic Oncol. 1995;345:540-543.

42. Zhang X, Xing JZ, Chen J, et al. Enhanced radiation sensitivity in prostate cancer by goldnanoparticles. Clin Invest Med. 2008;31(3):E160-E167.

43. Rahman WN, Bishara N, Ackerly T, et al. Enhancement of radiation effects by gold nanoparticles for superficial radiation therapy. Nanomedicine Nanotechnology, Biol Med. 2009;5(2):136-142. doi:10.1016/j.nano.2009.01.014.

44. Yasun E, Kang H, Erdal H, et al. Cancer cell sensing and therapy using affinity tag- 
conjugated gold nanorods. Interface Focus. 2013;3(3):20130006.

doi:10.1098/rsfs.2013.0006.

45. Yang C, Neshatian M, van Prooijen M, Chithrani D. Cancer nanotechnology: enhanced therapeutic response using peptide-modified gold nanoparticles. J Nanosci Nanotechnol. 2014;14(7):4813-4819. doi:10.1166/jnn.2014.9280.

46. Chithrani DB, Jelveh S, Jalali F, et al. Gold nanoparticles as radiation sensitizers in cancer therapy. Radiat Res. 2010;173(6):719-728. doi:10.1667/RR1984.1.

47. Butterworth KT, Wyer JA, Latimer CJ, et al. Variation of strand break yield for plasmid DNA irradiated with high-Z metal nanoparticles. Radiat Res. 2008;170(3):381-387.

48. Kaur H, Pujari G, Semwal MK, Sarma A, Avasthi DK. In vitro studies on radiosensitization effect of glucose capped gold nanoparticles in photon and ion irradiation of HeLa cells. Nucl Instruments Methods Phys Res Sect B. 2013;301:7-11. doi:10.1016/j.nimb.2013.02.015.

49. Lechtman E, Chattopadhyay N, Cai Z, Mashouf S, Reilly R, Pignol JP. Implications on clinical scenario of gold nanoparticle radiosensitization in regards to photon energy, nanoparticle size, concentration and location. Phys Med Biol. 2011;56(15):4631-4647. doi:10.1088/0031-9155/56/15/001.

50. Leung MKK, Chow JCL, Chithrani DB, Lee MJG, Oms B, Jaffray DA. Irradiation of gold nanoparticles by x-rays: Monte Carlo simulation of dose enhancements and the spatial properties of the secondary electrons production. Med Phys. 2011;38(2):624. doi:10.1118/1.3539623.

51. Jain S, Coulter JA, Hounsell AR, et al. Cell-specific radiosensitization by gold nanoparticles at megavoltage radiation energies. Int J Radiat Oncol Biol Phys. 2011;79(2):531-539. doi:10.1016/j.ijrobp.2010.08.044.

52. NIST. X-ray Mass Attenuation Coefficients.

53. Jain PK, Lee KS, El-Sayed IH, El-Sayed MA. Calculated absorption and scattering properties of gold nanoparticles of different size, shape, and composition: applications in biological imaging and biomedicine. J Phys Chem B. 2006;110(14):7238-7248. doi:10.1021/jp057170o.

54. Anderson R, Parrish J. The Optics of Human Skin. J Invest Dermatol. 1981;77:13-19.

55. El-Sayed MA. Some Interesting Properties of Metals Confined in Time and Nanometer Space of Different Shapes. Acc Chem Res. 2001;34(4):257-264. doi:10.1021/ar960016n.

56. Kelly KL, Coronado E, Zhao LL, Schatz GC. The Optical Propeties of Metal Nanoparticles: The Influence of Size, Shape and Dielectric Environment. J Phys Chem B. 2003;107:668-677.

57. Qin Z, Bischof JC. Thermophysical and biological responses of gold nanoparticle laser heating. Chem Soc Rev. 2012;41(3):1191-1217. doi:10.1039/c1cs15184c.

58. Lee KS, El-Sayed MA. Dependence of the enhanced optical scattering efficiency relative to that of absorption for gold metal nanorods on aspect ratio, size, end-cap shape, and 
medium refractive index. J Phys Chem B. 2005;109(43):20331-20338.

doi:10.1021/jp054385p.

59. Link S, Mohamed MB, El-Sayed MA. Simulation of the optical absorption spectra of gold nanorods as a function of their aspect ratio and the effect of the medium dielectric constant. J Phys Chem B. 1999;103(16):3073-3077. doi:10.1021/jp990183f.

60. Terentyuk GS, Maslyakova GN, Suleymanova L V, et al. Laser-induced tissue hyperthermia mediated by gold nanoparticles: toward cancer phototherapy. J Biomed Opt. 2009;14(2):021016. doi:10.1117/1.3122371.

61. Tarapacki C, Karshafian R. Enhancing laser therapy using PEGylated gold nanoparticles combined with ultrasound and microbubbles. Ultrasonics. 2014.

doi:10.1016/j.ultras.2014.10.015.

62. Huang X, El-Sayed IH, Qian W, El-Sayed M a. Cancer cell imaging and photothermal therapy in the near-infrared region by using gold nanorods. J Am Chem Soc. 2006;128(6):2115-2120. doi:10.1021/ja057254a.

63. Stern JM, Stanfield J, Kabbani W, Hsieh JT, Cadeddu JA. Selective prostate cancer thermal ablation with laser activated gold nanoshells. J Urol. 2008;179(2):748-753. doi:10.1016/j.juro.2007.09.018.

64. Stern JM, Stanfield J, Lotan Y, Park S, Hsieh JT, Cadeddu JA. Efficacy of laser-activated gold nanoshells in ablating prostate cancer cells in vitro. J Endourol. 2007;21(8):939-943. doi:10.1089/end.2007.0437.

65. Gobin AM, Moon JJ, West JL. EphrinA I-targeted nanoshells for photothermal ablation of prostate cancer cells. Int J Nanomedicine. 2008;3(3):351-358.

66. Dickerson EB, Dreaden EC, Huang X, et al. Gold nanorod assisted near-infrared plasmonic photothermal therapy (PPTT) of squamous cell carcinoma in mice. Cancer Lett. 2008;269(1):57-66. doi:10.1016/j.canlet.2008.04.026.

67. Hauck TS, Jennings TL, Yatsenko T, Kumaradas CJ, Chan WCW. Enhancing the toxicity of cancer chemotherapeutics with gold nanorod hyperthermia. Adv Mater. 2008;20(20):3832-3838. doi:10.1002/adma.200800921.

68. Harmon B V, Corder AM, Collins RJ, et al. Cell death induced in a murine mastocytoma by 42-47 degrees $C$ heating in vitro: evidence that the form of death changes from apoptosis to necrosis above a critical heat load. Int J Radiat Biol. 1990;58(5):845-858. doi:10.1080/09553009014552221.

69. Takano YS, Harmon B V., Kerr JFR. Apoptosis induced by mild hyperthermia in human and murine tumour cell lines: A study using electron microscopy and DNA gel electrophoresis. J Pathol. 1991;163(4):329-336. doi:10.1002/path.1711630410.

70. Chithrani DB. Intracellular uptake, transport, and processing of gold nanostructures. $\mathrm{Mol}$ Membr Biol. 2010;27(7):299-311. doi:10.3109/09687688.2010.507787.

71. Chattopadhyay N, Fonge H, Cai Z, et al. Role of antibody-mediated tumor targeting and route of administration in nanoparticle tumor accumulation in vivo. Mol Pharm. 2012;9:2168-2179. 
72. Alkilany AM, Nagaria PK, Hexel CR, Shaw TJ, Murphy CJ, Wyatt MD. Cellular uptake and cytotoxicity of gold nanorods: molecular origin of cytotoxicity and surface effects. Small. 2009;5(6):701-708. doi:10.1002/smll.200801546.

73. Chithrani DB, Ghazani AA, Chan WCW. Determining the size and shape dependence of gold nanoparticle uptake into mammalian cells. Nano Lett. 2006;6(4):662-668. doi:10.1021/n1052396o.

74. Antosh MP, Wijesinghe DD, Shrestha S, et al. Enhancement of radiation effect on cancer cells by gold-pHLIP. Proc Natl Acad Sci U S A. 2015;112(17):5372-5376. doi:10.1073/pnas.1501628112.

75. Yu MK, Park J, Jon S. Targeting strategies for multifunctional nanoparticles in cancer imaging and therapy. Theranostics. 2012;2(1):3-44. doi:10.7150/thno.3463.

76. Chithrani DB, Chan WCW. Elucidating the mechanism of cellular uptake and removal of protein-coated gold nanoparticles of different sizes and shapes. Nano Lett. 2007;7(6):1542-1550. doi:10.1021/n1070363y.

77. Reiter RE, Gu Z, Watabe T, et al. Prostate stem cell antigen: a cell surface marker overexpressed in prostate cancer. Proc Natl Acad Sci U S A. 1998;95(4):1735-1740.

78. Ling Y, Wei K, Luo Y, Gao X, Zhong S. Dual docetaxel/superparamagnetic iron oxide loaded nanoparticles for both targeting magnetic resonance imaging and cancer therapy. Biomaterials. 2011;32(29):7139-7150. doi:10.1016/j.biomaterials.2011.05.089.

79. Gao X, Luo Y, Wang Y, et al. Prostate stem cell antigen-targeted nanoparticles with dual functional properties: in vivo imaging and cancer chemotherapy. Int J Nanomedicine. 2012;7:4037-4051. doi:10.2147/IJN.S32804.

80. Jang SH, Wientjes MG, Lu D, Au JL. Drug Delivery and Transport to Solid Tumors. Pharm Res. 2003;20(9):1337-1350.

81. Maeda H, Wu J, Sawa T, Matsumura Y, Hori K. Tumor vascular permeability and the EPR effect in macromolecular therapeutics: a review. J Control Release. 2000;65(12):271-284. doi:10.1016/S0168-3659(99)00248-5.

82. Matsumura Y, Maeda H. A new concept for macromolecular therapeutics in cancer chemotherapy: mechanism of tumoritropic accumulation of proteins and the antitumor agent Smancs. Cancer Res. 1986;46:6387-6392.

83. Goodman TT, Olive PL, Pun SH. Increased nanoparticle penetration in collagenasetreated multicellular spheroids. Int J Nanomedicine. 2007;2(2):265-274.

84. Brannon-Peppas L, Blanchette JO. Nanoparticle and targeted systems for cancer therapy. Adv Drug Deliv Rev. 2004;56(11):1649-1659. doi:10.1016/j.addr.2004.02.014.

85. Niidome T, Yamagata M, Okamoto Y, et al. PEG-modified gold nanorods with a stealth character for in vivo applications. J Control Release. 2006;114(3):343-347. doi:10.1016/j.jconrel.2006.06.017.

86. Arnida, Malugin A, Ghandehari H. Cellular uptake and toxicity of gold nanoparticles in prostate cancer cells: a comparative study of rods and spheres. $J$ Appl Toxicol. 
2010;30(3):212-217. doi:10.1002/jat.1486.

87. Hainfeld JF, Lin L, Slatkin DN, Avraham Dilmanian F, Vadas TM, Smilowitz HM. Gold nanoparticle hyperthermia reduces radiotherapy dose. Nanomedicine. 2014;10(8):16091617. doi:10.1016/j.nano.2014.05.006.

88. Buckway B, Frazier N, Gormley AJ, Ray A, Ghandehari H. Gold nanorod-mediated hyperthermia enhances the efficacy of HPMA copolymer Y-90 conjugates in treatment of prostate tumors. Nucl Med Biol. 2014;41(3):282-289.

doi:10.1016/j.nucmedbio.2013.12.002.

89. Diagaradjane P, Shetty A, Wang JC, et al. Modulation of in vivo tumor radiation response via gold nanoshell-mediated vascular-focused hyperthermia: characterizing an integrated antihypoxic and localized vascular disrupting targeting strategy. Nano Lett. 2008;8(5):1492-1500. doi:10.1021/n1080496z.

90. Franken N a P, Rodermond HM, Stap J, Haveman J, van Bree C. Clonogenic assay of cells in vitro. Nat Protoc. 2006;1(5):2315-2319. doi:10.1038/nprot.2006.339.

91. Bliss CI. The Toxicity of Poisons Applied Jointly. Ann Appl Biol. 1939;26(3):585-615. doi:10.1111/j.1744-7348.1939.tb06990.x.

92. Chattopadhyay N, Cai Z, Kwon YL, Lechtman E, Pignol J-P, Reilly RM. Molecularly targeted gold nanoparticles enhance the radiation response of breast cancer cells and tumor xenografts to X-radiation. Breast Cancer Res Treat. 2013;137(1):81-91. doi:10.1007/s10549-012-2338-4.

93. Lechtman E, Mashouf S, Chattopadhyay N, et al. A Monte Carlo-based model of gold nanoparticle radiosensitization accounting for increased radiobiological effectiveness. Phys Med Biol. 2013;58(10):3075-3087. doi:10.1088/0031-9155/58/10/3075.

94. Cho EC, Liu Y, Xia Y. A simple spectroscopic method for differentiating cellular uptakes of gold nanospheres and nanorods from their mixtures. Angew Chem Int Ed Engl. 2010;49(11):1976-1980. doi:10.1002/anie.200906584.

95. Wilhelm S, Tavares AJ, Dai Q, et al. Analysis of nanoparticle delivery to tumours. Nat Rev Mater. 2016;1:16014. http://dx.doi.org/10.1038/natrevmats.2016.14. 